Federal Reserve Bank of Minneapolis

Research Department Staff Report 358

Revised February 2006

\title{
A Model of Job and Worker Flows
}

\author{
Nobuhiro Kiyotaki* \\ London School of Economics \\ and Federal Reserve Bank of New York
}

Ricardo Lagos*

Federal Reserve Bank of Minneapolis

and New York University

\begin{abstract}
We develop a model of gross job and worker flows and use it to study how the wages, permanent incomes, and employment status of individual workers evolve over time. Our model helps explain various features of labor markets, such as the amount of worker turnover in excess of job reallocation, the length of job tenures and unemployment duration, and the size and persistence of the changes in income that workers experience due to displacements or job-to-job transitions. We also examine the effects that labor market institutions and public policy have on the gross flows, as well as on the resulting wage distribution and employment in the equilibrium. From a theoretical standpoint, we propose a notion of competitive equilibrium for random matching environments, and study the extent to which it achieves an efficient allocation of resources.
\end{abstract}

${ }^{*}$ We thank Peter Diamond, Leonardo Felli, Bengt Holmstrom, Hidehiko Ichimura, Michihiro Kandori, Alessandro Lizzeri, George Mailath, John Moore, Barbara Petrongolo, Michele Piccione, Christopher Pissarides, Martin Schneider, and Gianluca Violante for helpful comments. Financial support from the C.V. Starr Center for Applied Economics at NYU is gratefully acknowledged. The views expressed herein are those of the authors and not necessarily those of the Federal Reserve Bank of Minneapolis, the Federal Reserve Bank of New York, or the Federal Reserve System. 


\section{Introduction}

Recent empirical and theoretical studies on gross job and worker flows have changed the way we think about the labor market. We now know that market economies exhibit high rates of reallocation of employment across establishments as well as high rates of worker turnover from one job to another and between employment and unemployment. We now view the number of employed or unemployed workers as resulting from a large and continual reallocation process, and we analyze how changes in the economic environment affect this process. The study of the gross flows provides valuable insights into how the labor market carries out this continual reallocation of resources, and at the same time raises many interesting questions: To what extent are market economies able to perform this reallocation process efficiently? How is this process affected by labor market policies?

The empirical literature distinguishes between measures of job flows and worker flows. In a series of influential studies using U.S. manufacturing census data, Davis and Haltiwanger (1992, 1999) and Davis, Haltiwanger and Schuh (1996) measure gross job creation $\left(J C_{t}\right)$ as the sum of employment gains over all plants that expand or start up between dates $t-1$ and $t$; gross job destruction $\left(J D_{t}\right)$ as the sum of employment losses over all plants that contract or shut down; and gross job reallocation as the sum of gross job creation and destruction $\left(J R_{t}=J C_{t}+J D_{t}\right)$. By showing that gross job creation and destruction are both large irrespective of whether aggregate employment grows or declines, their work highlights the role of heterogeneous forces

that cause employment to expand in some plants and contract in others. Behind these large job flows, however, are even larger worker flows.

Estimates of worker flows are based on establishment or on worker surveys, and measure the movements of workers across establishments and labor-market states. Empirical studies that draw on establishment data often define worker turnover at establishment $i\left(W T_{i t}\right)$ as the sum of the number of accessions (new hires) and separations (quits and displacements) between dates $t-1$ and $t$, and aggregate worker turnover $\left(W T_{t}\right)$ as the sum of worker turnover over 
establishments.

Alternatively, empirical studies that draw on worker surveys to estimate worker flows often define worker reallocation $\left(W R_{t}\right)$ as the number of workers who change employment states (i.e., who change place of employment, find or lose a job, or enter or exit the labor force) between dates $t-1$ and $t$. Worker turnover measures the number of labor market transitions, while worker reallocation counts the number of workers who participate in transitions. A worker who moves from one establishment to another increases the worker reallocation count by one and the aggregate worker turnover count by two; hence, aggregate worker turnover is larger than worker reallocation by the number of job-to-job transitions. ${ }^{1}$

Empirically, worker turnover is significantly larger than job reallocation. Drawing from different data sources for job and worker flows, Davis and Haltiwanger (1992) estimate that job creation and job destruction account for no less than one-third and no more than one-half of quarterly worker turnover in the U.S. manufacturing sector. New evidence from data sets that incorporate information on the number of accessions and separations at the establishment level indicates that for most establishments, for most of the time, worker turnover is much larger than job reallocation. Burgess, Lane and Stevens (2000), for example, refer to the difference between worker turnover and the net employment change as "churning" $\left(C_{i t}=W T_{i t}-\left|e_{i t}-e_{i t-1}\right|\right.$, where $e_{i t}$ is employment in establishment $i$ at the end of period $t$ ). This notion of churning measures the number of worker transitions in excess of the minimum needed to achieve the actual change in employment. Summing over establishments delivers an aggregate measure of churning: $C_{t}=W T_{t}-J R_{t}$. They use quarterly data from all private sector establishments in the state of Maryland and find that churning flows account for $70 \%$ of worker turnover in nonmanufacturing and about $62 \%$ in manufacturing (job reallocation accounts for the rest). ${ }^{2}$ From

\footnotetext{
${ }^{1}$ This is the case provided both the worker-side and establishment-side data sets cover the entire economy, and provided no accessions or separations are reversed within the sample period; else $W T_{t}-W R_{t}$ would be an upper bound for the number of job-to-job transitions.

${ }^{2}$ Similarly, based on data derived from the unemployment insurance systems of eight U.S. states, Anderson and Meyer (1994) report that gross job reallocation accounts for only $24 \%$ of quarterly worker turnover in manufacturing. Drawing from a data set covering the universe of Danish manufacturing plants, Albæk and Sørensen (1998) report a ratio of quarterly job reallocation to worker turnover of .42 and find that replacement
} 
an aggregate perspective, the amount of worker turnover in excess of job reallocation depends not only on the amount of simultaneous hiring and firing that takes place at the establishment level (e.g., as measured by $C_{i t}$ ), but also on the extent to which job-to-job transitions are a common mechanism through which the market achieves the reallocation of workers. In this respect, recent studies find that job-to-job flows are also large: Fallick and Fleischman (2001) estimate that in the United States in 1999, on average 4 million workers changed employers from one month to the next (about $2.7 \%$ of employment), more than twice the number who transited from employment to unemployment. The fact that worker flows exceed job flows at the establishment level is evidence of heterogeneity at the level of the employer-worker match - a layer of heterogeneity over and above the cross-establishment heterogeneity that can be inferred from the sheer size of the job flows alone.

The image that emerges is that of a labor market continuously reallocating employment positions across establishments (job reallocation), and workers across existing employment positions (worker turnover). This grand reallocation process often does not force workers to go through unemployment in order to switch employers, and does not require employment positions to become vacant in order to replace a worker. To us, all this suggests that in order to fully understand the workings of the labor market, we need to pry into the nature of job flows, worker flows, job-to-job transitions, and replacement hiring.

To this end, in this paper we develop a canonical equilibrium search model that incorporates job-to-job transitions, exhibits instances of replacement hiring, and conceptually distinguishes

hiring (defined as the sum of accessions minus job creation) is on average $16.5 \%$ of manufacturing employment. They also report interesting cross-establishment observations - for example, that $62 \%$ of all separations are accounted for by plants with employment growth rates in the interval $(-0.3,0.1]$ and that plants with employment growth rates in the interval $(-0.1,0.3]$ account for $56 \%$ of all hires. (Burgess, Lane and Stevens (2000) also present some establishment-level cross-sectional evidence, such as that most of the employers in their data set have churning rates above $50 \%$. See their Figure 1 on page 483 , which reports the distribution of $C_{i t} / W T_{i t}$.) Hamermesh, Hassink and van Ours (1996) find that job reallocation accounts for only one-third of worker turnover in a random sample of establishments in the Netherlands. They also find that most mobility is into and out of existing positions, not to new or from destroyed ones; that a large fraction of all hires (separations) take place at firms where employment is declining (expanding); and that simultaneous hiring is mostly due to unobservable heterogeneity in the workforce. 
between gross job and worker flows. ${ }^{3}$ A situation that arises naturally whenever agents can continue to search while matched, is one in which a matched agent contacts a new potential partner (who may also be matched) and each must decide whether to form a new match with the new partner or to stay with the old one. In a labor-market context, the employer who is trying to recruit an employed worker may have to face competition from the worker's current employer, and in addition, the recruiting employer's current employee may attempt to discourage this employer from replacing him with the new worker (e.g., by accepting a smaller share of the matching surplus). Natural as they may seem, these generic situations have not been systematically analyzed in the literature. ${ }^{4}$ One of the building blocks of our theory - and one of the contributions of this paper - is a simple and flexible noncooperative bargaining procedure that allows for competition among all parties taking part in such meetings. The equilibrium of the bargaining game we propose delivers the division of the gains from matching as well as privately efficient creation and destruction of matches.

Our second goal in this paper, in addition to developing a model of job and worker turnover, is to use the theory to explain various features of labor markets. For example, what determines the amount of worker turnover in excess of job reallocation? Why is it that worker turnover in Europe is substantially smaller than in the United States, whereas - despite the differences in labor-market policy regimes - job reallocation is roughly the same ${ }^{5}$ Why do displaced workers tend to experience a significant and persistent fall in incomes? Why do workers stay unemployed when on-the-job search is at least as effective as off-the-job search? Why are good jobs not only better paid, but often also more stable? In order to answer these questions we examine how

\footnotetext{
${ }^{3} \mathrm{Job}$ and worker reallocation are one and the same by construction in the workhorse of much of the recent macro-labor literature, the matching model of Diamond (1982b), Mortensen and Pissarides (1994) or Pissarides (2000). And there is no room for replacement hiring in the influential on-the-job search model of Burdett and Mortensen (1998).

${ }^{4}$ The first generation of job-search models assumed that agents could only search while unmatched, e.g., see Lippman and McCall (1976). However, Blau and Robins (1990) find that job-search while employed is no less effective than while unemployed. In Section 7, we explain how our work fits within the existing search literature that allows search while matched.

${ }^{5}$ This fact is documented in Bertola and Rogerson (1997), Blanchard and Portugal (2001), and Pries and Rogerson (2005).
} 
the employment status and wages of individual workers evolve over time, as well as the effects that labor market institutions and public policy have on the gross job and worker flows.

The rest of the paper is organized as follows. Section 2 lays out the environment and characterizes the efficient allocations. Section 3 introduces the notion of competitive matching equilibrium and characterizes its salient features. Section 4 incorporates employment protection policies, and Section 5 extends the model to allow for free entry of employers. For a special case, Section 6 provides a fuller characterization of the equilibrium set, discusses the main properties of the allocations, derives several labor-market implications, and shows how the model can help to rationalize many of the properties of job and worker flows documented in the empirical literature. Section 7 discusses the related literature. Section 8 concludes. The Appendix contains all proofs and explains some properties of the bargaining procedure we propose.

\section{The Model}

Time is continuous and the horizon is infinite. The economy is populated by a continuum of fixed and equal numbers of employers and workers. We normalize the size of each population to unity. Employers and workers are infinitely-lived and risk-neutral. They discount future utility at rate $r>0$, and are ex ante homogeneous in tastes and technology. (Although our main interest here is in the labor market, our model is applicable to any other setting where bilateral partnerships are relevant, such as the interactions between spouses, or between a tenant and a landlord, or between a supplier and the buyer of a customized product.)

A worker meets a randomly chosen employer according to a Poisson process with arrival rate $\alpha$. An employer meets a random worker according to the same process. ${ }^{6}$ Upon meeting, the employer-worker pair randomly draws a production opportunity of productivity $y$, which represents the flow net output each agent will produce while matched. (Thus the pair produces

\footnotetext{
${ }^{6}$ In general we can think of the total meeting rate as being equal to $\alpha \cdot($ population of employers) (population of workers). Here, because the populations of employers and workers are both unity, the rate at which a worker meets a randomly chosen employer equals the rate at which an employer meets a randomly chosen worker, and both equal $\alpha$, the total meeting rate. In this basic setup, employers and workers are completely symmetric. Below we analyze extensions where they differ in a variety of ways.
} 
$2 y$.) The random variable $y$ takes one of $N$ distinct values: $y_{1}, y_{2}, \ldots, y_{N}$, where $0<y_{1}<y_{2}<$ $\ldots<y_{N}$, and $y=y_{i}$ with probability $\pi_{i}$ for $i=1, \ldots, N$, and $\sum_{i=1}^{N} \pi_{i}=1$. The realization of the random variable $y$ that an employer and a worker draw when they first meet is observed without delay. We assume $y$ remains constant for the duration of the match.

Matched and unmatched agents meet potential partners at the same rate, so when an employer and a worker meet and draw a productive opportunity, each of them may or may not already be matched with an old production partner. Each agent can be in, at most, one productive partnership at any given time. The productivity of the new potential match as well as the productivities of the existing matches are public information to all the agents involved, i.e., the worker and the employer who draw the new productivity and their existing partners, if they have any. On the other hand, each agent's history is private information, except for what is revealed by the current production match.

When an employer and a worker draw a new production opportunity, the pair and their old partners (if they have any) determine whether or not the new match is formed (and consequently whether or not the existing matches are destroyed) as well as the once-and-for-all side payments that each party pays or receives, following a bargaining protocol which we will describe shortly. Utility is assumed to be transferable among all the agents involved in a meeting. There is no outside court to enforce any formal contract, so any effective contract must be self-enforcing among the parties involved. If the parties who made contact decide to form a new partnership, they leave their existing partners, who then become unmatched. In addition to these endogenous separations, we assume any match is subject to exogenous separation according to a Poisson process with arrival rate $\delta$.

We use $n_{i t}$ to denote the measure of matches of productivity $y_{i}$ and $n_{0 t}$ to denote the measure of unmatched employers or workers at date $t$. Let $\tau_{i j t}^{k}$ be the probability that a worker with current productivity $y_{i}$ and an employer with current productivity $y_{j}$ form a new match of productivity $y_{k}$, given that they draw an opportunity to produce $y_{k}$ at time $t$. (Hereafter, we will suppress the time subindex when no confusion arises.) The measure of workers in each 
state evolves according to:

$$
\begin{aligned}
& \dot{n}_{i}=\alpha \pi_{i} \sum_{j=0}^{N} \sum_{k=0}^{N} n_{j} n_{k} \tau_{j k}^{i}-\alpha n_{i} \sum_{j=0}^{N} \sum_{k=1}^{N} n_{j} \pi_{k}\left(\tau_{i j}^{k}+\tau_{j i}^{k}\right)-\delta n_{i} \\
& \dot{n}_{0}=\alpha \sum_{i=0}^{N} \sum_{j=1}^{N} \sum_{k=1}^{N} n_{i} n_{j} \pi_{k} \tau_{i j}^{k}+\delta \sum_{j=1}^{N} n_{j}-\alpha n_{0} \sum_{j=0}^{N} \sum_{k=1}^{N} n_{j} \pi_{k} \tau_{0 j}^{k} .
\end{aligned}
$$

The first term on the right side of (1) is the flow of new matches of productivity $y_{i}$ created by all types of workers and employers. The second term is the total flow of matches with productivity $y_{i}$ destroyed endogenously when the worker or the employer leaves to form a new match. The last term is the flow of matches dissolved exogenously. On the right side of equation (2), the first term is the flow of workers who become unmatched when their employers decide to break the current match to form a new match with another worker. The second term is the flow of workers who become unmatched due to the exogenous dissolution of matches. The third term is the flow of new matches created by employers and unemployed workers.

Before describing the competitive matching equilibrium with bargaining, we solve the social planner's problem. The planner chooses $\tau_{i j}^{k} \in[0,1]$ to maximize the discounted value of aggregate output:

$$
\int_{0}^{\infty} e^{-r t} \sum_{i=1}^{N} 2 y_{i} n_{i} d t
$$

subject to the flow constraints (1) and (2), and initial conditions for $n_{0}$ and $n_{i}$ for $i=1, \ldots, N$. Letting $\lambda_{i}$ be the shadow price of a match with productivity $y_{i}$ at date $t$, the Hamiltonian is

$$
H=\sum_{i=1}^{N} 2 y_{i} n_{i}-\delta \sum_{i=1}^{N}\left(\lambda_{i}-\lambda_{0}\right) n_{i}+\alpha \sum_{i=0}^{N} \sum_{j=0}^{N} \sum_{k=1}^{N} n_{i} n_{j} \pi_{k} \tau_{i j}^{k}\left(\lambda_{k}+\lambda_{0}-\lambda_{i}-\lambda_{j}\right) .
$$

The necessary conditions for optimality are

$$
\tau_{i j}^{k} \begin{cases}=1 & \text { if } \lambda_{k}+\lambda_{0}>\lambda_{i}+\lambda_{j} \\ \in[0,1] & \text { if } \lambda_{k}+\lambda_{0}=\lambda_{i}+\lambda_{j} \\ =0 & \text { if } \lambda_{k}+\lambda_{0}<\lambda_{i}+\lambda_{j}\end{cases}
$$


together with the Euler equations

$$
\begin{aligned}
r \lambda_{i}-\dot{\lambda}_{i} & =2 y_{i}-\delta\left(\lambda_{i}-\lambda_{0}\right)+\alpha \sum_{j=0}^{N} \sum_{k=1}^{N} n_{j} \pi_{k}\left(\tau_{i j}^{k}+\tau_{j i}^{k}\right)\left(\lambda_{k}+\lambda_{0}-\lambda_{i}-\lambda_{j}\right), \\
r \lambda_{0}-\dot{\lambda}_{0} & =\alpha \sum_{j=0}^{N} \sum_{k=1}^{N} n_{j} \pi_{k}\left(\tau_{0 j}^{k}+\tau_{j 0}^{k}\right)\left(\lambda_{k}-\lambda_{j}\right),
\end{aligned}
$$

and (1) and (2). According to (3), to achieve the optimal allocation, the planner specifies that a type $i$ worker and type $j$ employer should form a new match of productivity $y_{k}$ for sure if and only if the sum of the shadow prices of the new match and the unmatched worker and employee (which the new match would generate) exceeds the sum of the shadow prices of the existing matches of productivity $y_{i}$ and $y_{j}$. From (3) we also learn that $\tau_{i j}^{k}=\tau_{j i}^{k}$, except possibly for the case of randomized strategies. Intuitively, there is no inherent asymmetry between a worker and an employer, so the planner treats them symmetrically in the optimal allocation. These observations allow us to summarize the first order necessary conditions as:

$$
\begin{aligned}
r \lambda_{i}-\dot{\lambda}_{i} & =2 y_{i}-\delta\left(\lambda_{i}-\lambda_{0}\right)+2 \alpha \sum_{j=0}^{N} \sum_{k=1}^{N} n_{j} \pi_{k} \max _{\tau_{i j}^{k}} \tau_{i j}^{k}\left(\lambda_{k}+\lambda_{0}-\lambda_{i}-\lambda_{j}\right) \\
r \lambda_{0}-\dot{\lambda}_{0} & =2 \alpha \sum_{j=0}^{N} \sum_{k=1}^{N} n_{j} \pi_{k} \max _{\tau_{0 j}^{k}} \tau_{0 j}^{k}\left(\lambda_{k}-\lambda_{j}\right) .
\end{aligned}
$$

Equation (4) says that in the planner's problem, the flow return of a match of productivity $y_{i}$ equals the capital gain associated with the change of the shadow price plus the sum of the three terms on the right side: the flow output generated by the match, minus the expected loss from an exogenous separation, plus the expected gain from the endogenous creation and destruction of matches that occur when either of the agents in the match of productivity $i$ meets an agent in a match of productivity $j$ (which occurs at rate $2 \alpha n_{j}$ ) and draws productivity $y_{k}$ (with probability $\pi_{k}$ ). The flow return of a pair of unmatched agents in (5) is similar but output is zero and there is no loss resulting from exogenous separation. 


\section{Competitive Matching Equilibrium}

In a decentralized economy, the creation and destruction of matches depends on how the gains from trade are divided among the agents who find a new production opportunity and their old partners (if they have any). In this section we propose a notion of equilibrium where the prevailing matches are determined, and the gains from trade are apportioned, through the following bargaining procedure.

When a worker and an employer find a new production opportunity, a move by Nature first determines, with equal probability, whether the worker(s) or the employer(s) have the bargaining power. The agents with the new production opportunity then choose whether to bargain first with the new potential partner or with the old partner, if there is one. ${ }^{7}$ All negotiations are bilateral, either between new potential partners or between old partners. Once the bargaining pairs have been decided, the agent with the bargaining power makes an offer which consists of a proposal to produce together and a division of surplus to be implemented through spot side payments. The recipient of the offer chooses whether to accept, reject, or continue to negotiate with the alternative partner (if there is one), withholding the received offer as her outside option. An outstanding offer is public information, and cannot be revised later. If the offer is rejected, then the agent who has an alternative partner will negotiate without the outside option.

The second round of bilateral bargaining, with or without outside option(s), is similar to the first round: The agent with the bargaining power makes an offer, and the recipient either accepts or rejects it. If an offer is rejected, the recipient then makes a final choice of whether to accept or reject the withheld offer (if she has one). The bargaining ends either when an offer is accepted, or when there is no alternative partner to bargain with after rejection (in which case there will be no match for production). The bargaining does not take time: the entire

\footnotetext{
${ }^{7}$ If one of the agents with the option to form a new match chooses to bargain with her old partner first, while the other one chooses to bargain with his new partner first, then the latter will wait until the former comes to bargain with him.
} 
process finishes instantaneously. We specify that as long as neither encounters a new production opportunity, matched agents split output equally. ${ }^{8}$ There is no outside court to enforce formal contracts, so agents can walk away from a match at any time without penalty. (In Section 4 we introduce a government that imposes a tax on every employer who separates from a worker.)

A competitive matching equilibrium is a set of bargaining strategies specifying a sequencing of bargaining partners, how much utility to offer bargaining partners in order to produce together, and whether to accept, reject, or withhold a received offer, together with a population distribution of partnerships such that: (a) taking the population distribution and the bargaining strategies of the other agents as given, each agent chooses her bargaining strategies in order to maximize her expected discounted utility; and (b) given the agents' bargaining strategies, the population distribution satisfies (1) and (2).

Three different types of meetings can result from the random matching process: (i) a meeting between an unmatched worker and an unmatched employer, (ii) a meeting between a matched agent and an unmatched agent, or (iii) a meeting between a matched worker and a matched employer. Since creating a new match entails destroying one existing match in situation (ii) and two existing matches in situation (iii), we follow Diamond and Maskin (1979), and refer to the former as a "single breach" and to the latter as a "double breach." Since a worker and an employer who form a match are inherently symmetric, we will restrict attention to equilibria in which workers and employers are treated symmetrically and agents are distinguished only by the productivity of their current match. We will refer to a match of productivity $y_{i}$ as a "type $i$ match," and call a worker or an employer in a type $i$ match a "type $i$ agent." Let $V_{i}$ be the value of expected discounted utility of a type $i$ agent, and let $V_{0}$ be the value of an unmatched agent. We begin by describing the bargaining outcomes for each of the three types of meetings, taking $V_{i}$ and $V_{0}$ as given. We will then specify how these values are determined in equilibrium.

\footnotetext{
${ }^{8}$ Equivalently, we can think of the matched pair without an outside production opportunity as being involved in continual negotiations by which the expected value of side payments nets out to be zero. (See the proof of Proposition 3 for more on this.)
} 


\section{(i). An unmatched worker and an unmatched employer draw an opportunity.}

Suppose that an unemployed worker and an employer with a vacancy draw an opportunity for each to produce $y_{k}$. Since both are unmatched, the outside option to each agent is $V_{0}$. This case is illustrated in Figure 1, where we have named the two agents involved in this meeting $A$ and $B$. Let $X_{i j}^{k}$ be the value that agent $i$ offers agent $j$ in order to form (or preserve) a match of productivity $y_{k}$. Specifically, $X_{i j}^{k}$ includes the value of the match plus the net side payment agent $i$ pays to agent $j$. The bargaining unfolds as follows. With probability a half, $A$ makes a take-it-or-leave-it offer $X_{A B}^{k}$ to $B$. Clearly, $A$ will choose this offer in order to maximize her own utility, subject to the constraint that $B$ will accept. Hence, $A$ offers $X_{A B}^{k}=V_{0}$, and $B$ accepts. With the same probability, $B$ makes an offer $X_{B A}^{k}=V_{0}$ to $A$, which is again accepted.

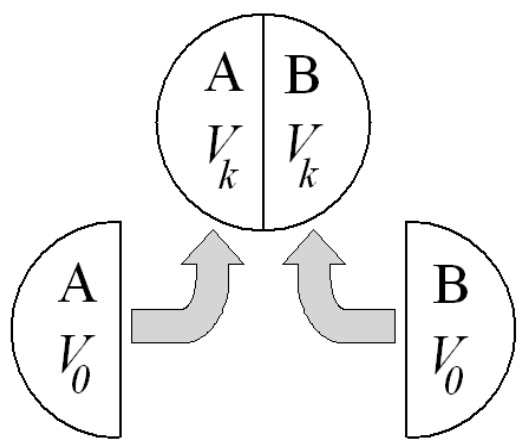

Figure 1: An unmatched employer meets an unmatched worker.

Let $\Pi_{i}$ be the expected payoff to agent $i$ and $\Gamma_{i}$ be her expected gain. Then, $\Pi_{A}=\Pi_{B}=$ $\frac{1}{2} V_{0}+\frac{1}{2}\left(2 V_{k}-V_{0}\right)=V_{k}$, and $\Gamma_{A}=\Gamma_{B}=V_{k}-V_{0}$. In this symmetric situation the expected value of the side payment is zero, and both unmatched agents enjoy the same expected capital gains from forming the new match.

\section{(ii). A matched agent and an unmatched agent draw an opportunity.}

Suppose that worker $B$, who is currently in a match of productivity $y_{i}$ with employer $A$, 
meets employer $C$, who has vacancy, and they draw a productive opportunity $y_{k}$. This situation is illustrated in Figure 2.

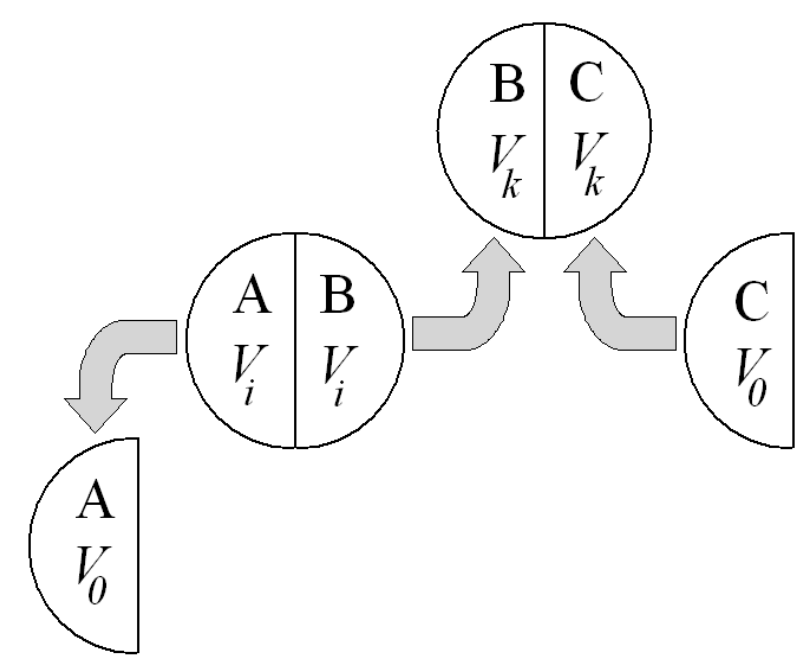

Figure 2: Single breach.

We consider two cases.

Case 1: $V_{k}>V_{i}$. Depending upon Nature's draw, with equal probability, either worker $B$ has bargaining power, or employers $A$ and $C$ have bargaining power. When worker $B$ has bargaining power, $B$ proposes the new partner $C$ to match, offering $X_{B C}^{k}=V_{0}$. Employer $C$ accepts this offer, and $B$ appropriates all the surplus from the new match, $2 V_{k}-V_{0}$. When instead employers $A$ and $C$ have bargaining power, because the new potential match has higher value than the existing one, $B$ chooses to bargain with the new employer, $C$, first. When choosing $X_{C B}^{k}$, the new employer keeps in mind that $B$ can continue to bargain with his old employer $(A)$ with $X_{C B}^{k}$ as his outside option: the old employer $(A)$ will outbid $C$ as long as paying $X_{C B}^{k}$ to continue matching with $B$ is better than becoming unmatched, i.e., as long as $2 V_{i}-X_{C B}^{k}>V_{0}$. So in order for $C$ to win $B$ over $A, C$ 's offer has to be at least as large as $2 V_{i}-V_{0}$, therefore $X_{C B}^{k}=2 V_{i}-V_{0}$ and $A$ cannot outbid $C$. (If $A$ was to offer $B$ more than $2 V_{i}-V_{0}$, her value of continuing matching with $B$ would be less than the value of being 
unmatched.) Notice that regardless of which agent(s) have the bargaining power, $B$ 's payoff from matching with $C$ will be larger than $2 V_{i}-V_{0}$, the maximum he can get from matching with $A$. Thus, in the equilibrium, $B$ and $C$ create the new match while $A$ becomes unmatched. The expected gains are:

$$
\begin{aligned}
\Gamma_{A} & =-\left(V_{i}-V_{0}\right) \\
\Gamma_{B} & =\frac{1}{2}\left[\left(2 V_{k}-V_{0}\right)+\left(2 V_{i}-V_{0}\right)\right]-V_{i}=V_{k}-V_{0}, \\
\Gamma_{C} & =\frac{1}{2}\left[V_{0}+\left(2 V_{k}-2 V_{i}+V_{0}\right)\right]-V_{0}=V_{k}-V_{i} .
\end{aligned}
$$

Note that through the side payment of transferable utility, the expected gains to the agents who form the new match are equal to the capital gains of the new partner instead of their own capital gains: the gain to $B$ is $V_{k}-V_{0}$ and the gain to $C$ is $V_{k}-V_{i}$, so $B$, who is in a stronger bargaining position, enjoys a larger gain than $C$. On the other hand, $A$ suffers a capital loss from becoming unmatched without receiving any compensation (there is no reason for the new pair to pay $A$ since $B$ can walk away without any penalty). ${ }^{9}$

Case 2: $V_{i}>V_{k}$. Again, depending upon Nature's draw and with equal probability, either worker $B$ has bargaining power, or employers $A$ and $C$ have bargaining power. When $B$ has bargaining power, he makes an offer $X_{B A}^{i}=V_{0}$ to $A$, which is accepted, and $B$ monopolizes all the surplus, $2 V_{i}-V_{0}$. When the employers $A$ and $C$ have bargaining power, $B$ chooses to bargain with his old employer, $A$, first, since the old match is better than the new match. The old employer makes an offer $X_{A B}^{i}$ to $B$, who can continue to bargain with $C$ holding $X_{A B}^{i}$ as

\footnotetext{
${ }^{9}$ We derived the equilibrium gains under the presumption that $B$ will bargain with "the winner" (in this case $C$ ) first, both when $B$ has bargaining power and when $A$ and $C$ do. Suppose that $A$ and $C$ have bargaining power, and that $B$ instead chooses to bargain with $A$ first. Since $A$ knows she will lose (because the maximum payoff she is willing to offer $B$ is $2 V_{i}-V_{0}$ while $C$ can bid up to $\left.2 V_{k}-V_{0}\right), A$ is indifferent between making any offer $X_{A B}^{i}$ such that $X_{A B}^{i} \leq 2 V_{i}-V_{0}$. In particular, she may make a "lousy" offer to $B, X_{A B}^{i}<2 V_{i}-V_{0}$. If $A$ does this, then $B$ will find himself in a weak bargaining position when he goes on to negotiate with $C$. Thus $B$ will not gain from negotiating first with the loser, $A$, because the most $B$ can receive from $A$ is $X_{A B}^{i}=2 V_{i}-V_{0}$, which is the minimum payoff $B$ can get from negotiating first with the winner, $C$. The upshot is that in every case, the equilibrium outcomes (match creation and destruction decisions and expected payoffs) are always uniquely determined, and are those which are induced by the equilibrium in which $B$ always chooses to bargain with the "winner" first.
} 
an outside option. When choosing $X_{A B}^{i}, A$ takes into account that the new employer, $C$, will outbid $X_{A B}^{i}$ if and only if paying $X_{A B}^{i}$ in order to form the new match with $B$ is better than remaining unmatched, i.e., if $2 V_{k}-X_{A B}^{i}>V_{0}$. Thus, in order for $A$ to win $B$ over $C, A$ chooses to pay $X_{A B}^{i}=2 V_{k}-V_{0}$. Regardless of which side has bargaining power, $B$ 's payoff from staying with $A$ is larger than the payoff he can get by matching with $C$. Therefore, $A$ and $B$ remain matched, while $C$ stays unmatched. The expected gains are:

$$
\begin{aligned}
\Gamma_{A} & =\frac{1}{2}\left[V_{0}+\left(2 V_{i}-2 V_{k}+V_{0}\right)\right]-V_{i}=-\left(V_{k}-V_{0}\right) \\
\Gamma_{B} & =\frac{1}{2}\left[\left(2 V_{i}-V_{0}\right)+\left(2 V_{k}-V_{0}\right)\right]-V_{i}=V_{k}-V_{0}, \\
\Gamma_{C} & =V_{0}-V_{0}=0 .
\end{aligned}
$$

Although the current match is not destroyed, the old partner, $A$, has to buy out $B$ 's expected gains from matching with $C$ (by making a utility side payment with expected value equal to $\left.V_{k}-V_{0}\right)$ in order to persuade $B$ to stay in the current match. ${ }^{10}$

When we compare the sum of expected payoffs of all agents, we have $\Pi_{A}+\Pi_{B}+\Pi_{C}=V_{0}+2 V_{k}$ when the new match is formed, and $\Pi_{A}+\Pi_{B}+\Pi_{C}=2 V_{i}+V_{0}$ when the old match continues. In both cases, $V_{k}>V_{i}$ and $V_{i}>V_{k}$, the match with higher value prevails in the equilibrium. Here, with fully transferable utility, the Coase Theorem holds: the total sum of payoffs of all the agents involved in the meeting is maximized under the bargaining procedure of our competitive matching equilibrium, for given values of $V_{j}$ s. The Coase Theorem continues to hold in the case of double breach, to which we turn next.

\section{(iii). A matched worker and a matched employer draw an opportunity.}

Suppose that worker $B$ and employer $C$ meet and draw a productive opportunity $y_{k}$. The situation now is that $B$ is currently in a match of productivity $y_{i}$ with employer $A$, while $C$ is currently in a match of productivity $y_{j}$ with worker $D$. This is illustrated in Figure 3.

\footnotetext{
${ }^{10}$ In the above analysis, we have assumed that the matched agent with the outside opportunity to form a new match is a worker; i.e., $B$ was a worker, and $A$ and $C$ employers. But because workers and employers are symmetric, the gains from the trade will be the same if instead, $A$ and $C$ are workers and $B$ is an employer.
} 


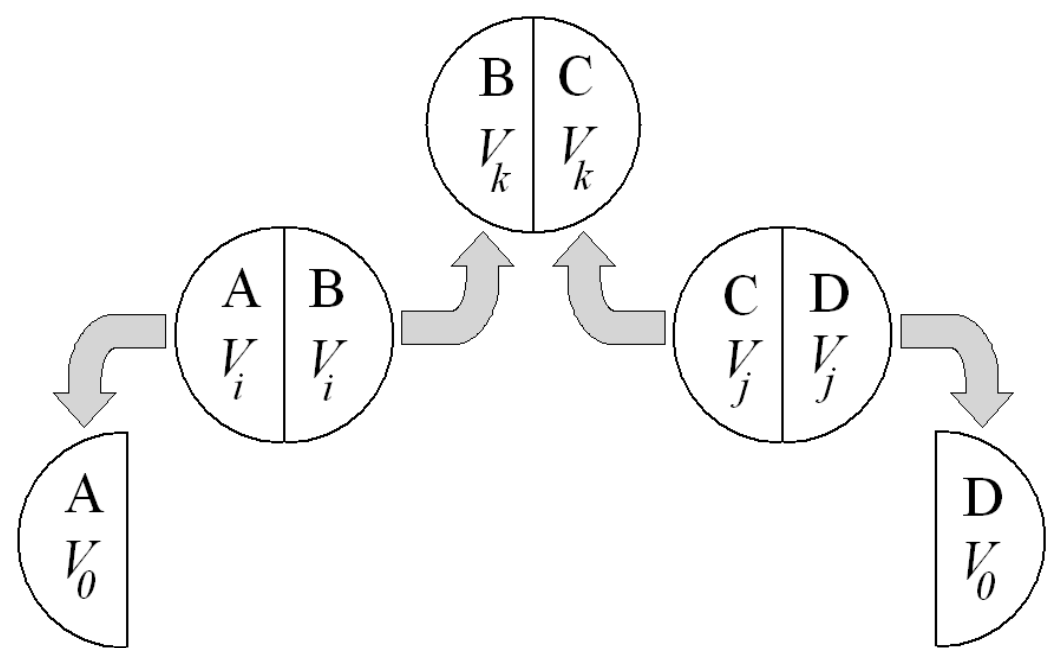

Figure 3: Double breach.

Case 1: $V_{k}+V_{0}>V_{i}+V_{j}$. Because the sum of the values of the new match and the unmatched exceeds the sum of the values of the old matches, the agent who does not have bargaining power chooses to bargain with the new partner first. ${ }^{11}$ With probability a half, the draw by Nature determines that the workers, $B$ and $D$, have bargaining power, so worker $B$ makes an offer $X_{B C}^{k}$ to $C$. Employer $C$ can continue to bargain with her old worker $D$ with $X_{B C}^{k}$ as her outside option. Worker $D$ will outbid worker $B$ if paying $X_{B C}^{k}$ to maintain the old match is better than becoming unmatched, i.e., if $2 V_{j}-X_{B C}^{k}>V_{0}$. Therefore, in order for $B$ to win $C$ over $D, B$ chooses to offer $X_{B C}^{k}=2 V_{j}-V_{0}$ (the maximum payoff $D$ is willing to pay to $C$ ). Alternatively, with probability a half it is the employers, $A$ and $C$, who have bargaining power. In this case $C$ makes an offer $X_{C B}^{k}$ to $B$, and the same reasoning leads to $X_{C B}^{k}=2 V_{i}-V_{0}$ (the maximum payoff $A$ is willing to offer $B$ ). Note that regardless of who has bargaining power, if they match together, both $B$ and $C$ receive a payoff that is larger than the maximum they can get from their old partners. Thus, $B$ and $C$ will form the new match, while $A$ and $D$ will

\footnotetext{
${ }^{11}$ The agent who has bargaining power does not have to be careful about the order in which she bargains with her alternative partners, because she can obtain all the surplus from matching with the new partner in any case.
} 
become unmatched. ${ }^{12}$ The expected gains are:

$$
\begin{aligned}
\Gamma_{A} & =-\left(V_{i}-V_{0}\right), \\
\Gamma_{B} & =\frac{1}{2}\left[\left(2 V_{i}-V_{0}\right)+\left(2 V_{k}-2 V_{j}+V_{0}\right)\right]-V_{i}=V_{k}-V_{j}, \\
\Gamma_{C} & =\frac{1}{2}\left[\left(2 V_{k}-2 V_{i}+V_{0}\right)+\left(2 V_{j}-V_{0}\right)\right]-V_{j}=V_{k}-V_{i}, \\
\Gamma_{D} & =-\left(V_{j}-V_{0}\right) .
\end{aligned}
$$

Case 2: $V_{k}+V_{0}<V_{i}+V_{j}$. Since the sum of the values of the existing matches exceeds the sum of the values of the new match and the unmatched, the agent without bargaining power chooses to bargain with the old partner first. With probability one-half, employers $A$ and $C$ have bargaining power. In this case, worker $B$ chooses to bargain first with his old employer, $A$. When choosing $X_{A B}^{i}, A$ takes into account the fact that $B$ can continue to bargain with the new potential employer, $C$, withholding $X_{A B}^{i}$ as his outside option. $A$ knows that $C$ will outbid $X_{A B}^{i}$ as long as $C$ 's payoff from forming the new match with $B$ by paying $X_{A B}^{i}$, namely $2 V_{k}-X_{A B}^{i}$, is higher than $C$ 's payoff from staying matched with $D, 2 V_{j}-V_{0}$ (since $C$ has bargaining power). Therefore, in order for $A$ to win $B$ over $C$, her offer must satisfy $X_{A B}^{i}=\operatorname{Max}\left(V_{0}, 2 V_{k}-2 V_{j}+V_{0}\right)$, where $V_{0}$ is included in Max in order to guarantee that $A$ 's offer leaves $B$ at least as well off as he would be by becoming unmatched $\left(2 V_{k}-2 V_{j}+V_{0}<V_{0}\right.$ if $V_{k}<V_{j}$, but $A$ still wants $B$ to accept her offer, because preserving the existing match by paying $V_{0}$ is better than becoming unmatched). Alternatively, with probability one half, it is workers $B$ and $D$ who have bargaining power. In this case, employer $C$ chooses to bargain with her old worker, $D$, first. The same argument applies to the bargaining between $C$ and $D$.

\footnotetext{
${ }^{12}$ Here, although in principle $A$ and $D$ can meet, they cannot form a productive match unless they have drawn a production opportunity together. In other words, to be able to engage in joint production, two agents must draw a production opportunity in addition to just meeting. In any case, allowing for the possibility that $A$ and $D$ have a production opportunity simultaneously with $B$ and $C$ 's will not change our result, since the probability of such an event is negligible relative to that of the event of a single pair having the opportunity.
} 
Taken together, the expected gains are

$$
\begin{aligned}
\Gamma_{A} & =\frac{1}{2}\left[2 V_{i}-\operatorname{Max}\left(V_{0}, 2 V_{k}-2 V_{j}+V_{0}\right)+V_{0}\right]-V_{0} \\
\Gamma_{B} & =\frac{1}{2}\left[\operatorname{Max}\left(V_{0}, 2 V_{k}-2 V_{j}+V_{0}\right)+\left(2 V_{i}-V_{0}\right)\right]-V_{i} \\
\Gamma_{C} & =\frac{1}{2}\left[\left(2 V_{j}-V_{0}\right)+\operatorname{Max}\left(V_{0}, 2 V_{k}-2 V_{i}+V_{0}\right)\right]-V_{j} \\
\Gamma_{D} & =\frac{1}{2}\left[V_{0}+2 V_{j}-\operatorname{Max}\left(V_{0}, 2 V_{k}-2 V_{i}+V_{0}\right)\right]-V_{0}
\end{aligned}
$$

Figure 4 summarizes the expected gains from trade in double-breach situations. (The figure assumes $V_{i}<V_{j}$, without loss of generality.)

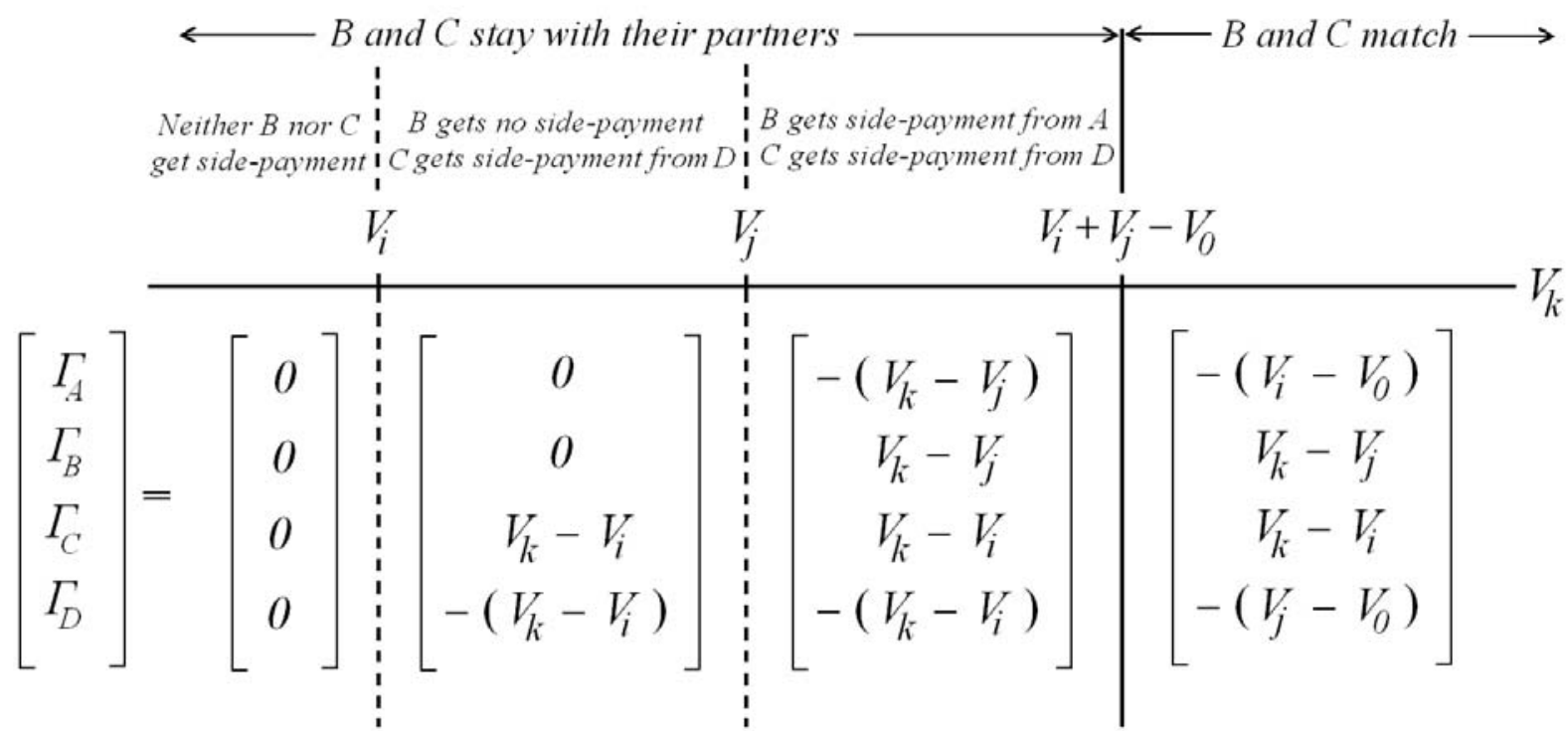

Figure 4: Double breach: expected capital gains.

If $V_{i}+V_{j}-V_{0}<V_{k}$, then $B$ and $C$ form a new match. The equilibrium expected side payment between them is such that the expected gains to each of them is equal to the capital gains to the new partner, instead of their own capital gain. ${ }^{13}$ When $V_{j}<V_{k}<V_{i}+V_{j}-V_{0}$, although

\footnotetext{
${ }^{13}$ If $B$ and $C$ were to form a new match and there were no side payments, then $B$ would gain $V_{k}-V_{i}$ and $C$ would gain $V_{k}-V_{j}$, but the equilibrium side payments imply that these gains are swapped: $B$ gains $V_{k}-V_{j}$ and $C$ gains $V_{k}-V_{i}$. So when a new match is formed, the agent who is currently in the better match enjoys a larger capital gain.
} 
the existing matches continue, the old partner must, on average, pay his current partner her opportunity cost of giving up the option to form a new match. When $V_{i}<V_{k}<V_{j}$, because the value of the new potential match is not as large as the value of the existing match between $C$ and $D$, on average, $A$ does not have to pay a side payment to $B$ in order to persuade him to stay in the existing match. But in expectation, $D$ still needs to pay a side payment to $C$ in order to preserve their valuable match. When $V_{k}<V_{i}$, the value of the new potential match between $B$ and $C$ is so small that on average, $A$ does not have to make a side payment to $B$, and $D$ does not have to make a side payment to $C$.

We summarize the main features of the bargaining outcomes in Proposition 1. The proof of parts (a) and (b) follows from the above discussion. Part (c) is proved in the Appendix, which also provides a graphical analysis of the bargaining procedure.

Proposition 1 For given value functions, the matching decisions and side payments are uniquely determined in the symmetric competitive matching equilibrium through the sequence of bilateral bargaining. Moreover,

(a) When two agents find an opportunity to form a new match, they form the new match and displace their existing partners (if they have any) if and only if the sum of the values of the new match and the unmatched exceeds the total value of the existing matches.

(b) Through the side payment, the expected net gain to the agent who forms a new match is equal to the capital gains of the new partner (instead of her own capital gains).

(c) The equilibrium outcomes (and expected outcomes) induced by the sequence of bilateral bargaining lie in the core.

The bulk of the search and matching literature follows the seminal work of Diamond and Maskin (1979), Diamond (1982a), and Pissarides (1984) in assuming that agents share rents according to the axiomatic Nash solution. But the explicit bargaining procedure we propose seems more appealing for environments with richer interactions among agents (such as double breaches) in which the equilibrium match-formation decisions and the agents' outside options 
are not obvious, since our procedure determines them endogenously along with the surplus sharing. ${ }^{14}$ In an environment with limited commitment like the one we analyze, this bargaining procedure is also more appealing than some popular cooperative solution concepts such as the Shapley value. According to the Shapley value, the winning pair generally leaves some surplus to the losing partner(s), which is not rational for the winners since they can walk away from their current matches without penalty.

There is a strand of the matching literature with on-the-job search that considers the special case of single breach in which two employers compete for a single worker. This literature assumes that when these situations arise, employers engage in Bertrand competition for the worker (e.g., Dey and Flinn (2005), Postel-Vinay and Robin (2002)). For this special case, the equilibrium outcomes of the bargaining procedure we propose coincide with the ones implied by Bertrand competition. But in addition, our bargaining game can resolve situations with richer interactions among agents, such as double breaches. ${ }^{15}$

In equilibrium, individual agents' expected payoffs satisfy the following Bellman equations:

$$
\begin{aligned}
r V_{i}-\dot{V}_{i}= & y_{i}+\alpha \sum_{j=0}^{N} \sum_{k=1}^{N} n_{j} \pi_{k}\left[\phi_{i j}^{k}\left(V_{k}+s_{i j}^{k}-V_{i}\right)+\left(1-\phi_{i j}^{k}\right) z_{i j}^{k}\right] \\
& -\alpha \sum_{j=0}^{N} \sum_{k=1}^{N} n_{j} \pi_{k}\left[\phi_{j i}^{k}\left(V_{i}-V_{0}\right)+\left(1-\phi_{j i}^{k}\right) z_{i j}^{k}\right]-\delta\left(V_{i}-V_{0}\right)
\end{aligned}
$$

for $i=1, \ldots, N$, and

$$
r V_{0}-\dot{V}_{0}=\alpha \sum_{j=0}^{N} \sum_{k=1}^{N} n_{j} \pi_{k} \phi_{0 j}^{k}\left(V_{k}+s_{0 j}^{k}-V_{0}\right) .
$$

\footnotetext{
${ }^{14}$ See footnote 17 below for more on this.

${ }^{15}$ In a previous version of this paper we devised a notion of equilibrium based on a variant of Bertrand competition that can be applied to all our matching situations, including double breaches. To illustrate, consider the situation depicted in Figure 3. The structure of the competition we considered specified that with probability one-half, $A$ and $C$ have bargaining power. In this case, $A$ makes a take-it-or-leave-it offer to $B$, and simultaneously, $C$ makes an offer to $B$ and to $D$-with $C$ 's offer to $D$ being contingent on $B$ 's rejection. (Alternatively, with probability one-half $B$ and $D$ have bargaining power, etc.) The equilibrium match-creation and destruction decisions and the expected payoffs induced by this Bertrand-like scheme turn out to be identical to those induced by the bargaining procedure we have adopted here. We favor the sequential bilateral bargaining procedure where agents can hold outside offers for two reasons. First, it seems to more closely resemble actual negotiations involving offers and counter-offers. Second, the Bertrand scheme relies on the agents' ability to make two simultaneous offers (even though they can match with only one of the candidates), with one of the offers being conditional on the other offer being rejected - a feature that is not characteristic of actual employment offers.
} 
Consider, for example, the most general situation illustrated in Figure 3. The return of agent $B$, who is in a match of type $i$ with agent $A$, in equation (6) includes his share of the flow output generated by the match, $y_{i}$, plus the expected capital gains he experiences when meeting other potential partners, minus the expected capital losses he suffers when his partner meets other potential partners, or when the match is destroyed exogenously. The choice of a worker in a match of type $i$ and an employer in a match of type $j$ to form a new match of type $k$ is represented by $\phi_{i j}^{k} \in[0,1]$. Conditional on $B$ having met a new partner, $n_{j}$ is the probability that this new partner is in a match of type $j$, and $\pi_{k}$ is the probability that the employer-worker pair draws an opportunity of type $k$. If the new match is formed, then $B$ gains $V_{k}-V_{i}$ plus $s_{i j}^{k}$, which denotes the expected (net) side payment that $B$ receives from the new partner to form a new match of type $k$, implied by the bargaining procedure we outlined earlier. (Thus, $s_{i j}^{k}=-s_{j i}^{k}$.) If the match is not formed, then $B$ may receive an expected side payment $z_{i j}^{k}$ from his current partner, $A$. The collection of negative terms are the expected losses $B$ experiences when $A$ contacts other agents. For instance, if $A$ meets another agent currently in a match of type $j$ and they decide to form a new match of type $k$ (which they do with probability $\phi_{j i}^{k}$ ), then $B$ gets displaced and loses $V_{i}-V_{0}$. Alternatively, $B$ may be able to persuade $A$ to stay in the current match by paying her a side payment with expected value $z_{i j}^{k} .{ }^{16}$

From part (a) of Proposition 1 we know that $\phi_{i j}^{k}=\phi_{j i}^{k}$, and $\phi_{i j}^{k}\left(V_{k}+V_{0}-V_{i}-V_{j}\right)=$ $\max _{\phi_{i j}^{k}} \phi_{i j}^{k}\left(V_{k}+V_{0}-V_{i}-V_{j}\right)$, and from part (b) that $V_{k}+s_{i j}^{k}-V_{i}=V_{k}-V_{j}$, so the value functions (6) and (7) reduce to

$$
\begin{aligned}
r V_{i}-\dot{V}_{i} & =y_{i}-\delta\left(V_{i}-V_{0}\right)+\alpha \sum_{j=0}^{N} \sum_{k=1}^{N} n_{j} \pi_{k} \max _{\phi_{i j}^{k}} \phi_{i j}^{k}\left(V_{k}+V_{0}-V_{i}-V_{j}\right) \\
r V_{0}-\dot{V}_{0} & =\alpha \sum_{j=0}^{N} \sum_{k=1}^{N} n_{j} \pi_{k} \max _{\phi_{0 j}^{k}} \phi_{0 j}^{k}\left(V_{k}-V_{j}\right)
\end{aligned}
$$

\footnotetext{
${ }^{16}$ Strictly speaking, our convention to use $\phi_{i j}^{k}$ to denote the probability that a worker in a match of type $i$ and an employer in a match of type $j$ choose to form a new match of type $k$ means that (6) and (7) are the value functions of a worker. The value functions corresponding to the employer are the same, except that $\phi_{i j}$ is replaced by $\phi_{j i}$ everywhere on the right-hand sides of (6) and (7).
} 
and the value of a match to the pair, $\lambda_{i}^{c}=2 V_{i}$, satisfies

$$
\begin{aligned}
r \lambda_{i}^{c}-\dot{\lambda}_{i}^{c} & =2 y_{i}-\delta\left(\lambda_{i}^{c}-\lambda_{0}^{c}\right)+\alpha \sum_{j=0}^{N} \sum_{k=1}^{N} n_{j} \pi_{k} \max _{\phi_{i j}^{k}} \phi_{i j}^{k}\left(\lambda_{k}^{c}+\lambda_{0}^{c}-\lambda_{i}^{c}-\lambda_{j}^{c}\right) \\
r \lambda_{0}^{c}-\dot{\lambda}_{0}^{c} & =\alpha \sum_{j=0}^{N} \sum_{k=1}^{N} n_{j} \pi_{k} \max _{\phi_{0 j}^{k}} \phi_{0 j}^{k}\left(\lambda_{k}^{c}-\lambda_{j}^{c}\right) .
\end{aligned}
$$

With this notation, part (a) of Proposition 1 can be written as:

$$
\phi_{i j}^{k} \begin{cases}=1 & \text { if } \lambda_{k}^{c}+\lambda_{0}^{c}>\lambda_{i}^{c}+\lambda_{j}^{c} \\ \in[0,1] & \text { if } \lambda_{k}^{c}+\lambda_{0}^{c}=\lambda_{i}^{c}+\lambda_{j}^{c} \\ =0 & \text { if } \lambda_{k}^{c}+\lambda_{0}^{c}<\lambda_{i}^{c}+\lambda_{j}^{c} .\end{cases}
$$

The competitive matching equilibrium can now be summarized by a list $\left(\lambda_{i}^{c}, \phi_{i j}^{k}, n_{i}\right)$ for $i, j=$ $0, \ldots, N$ and $k=1, \ldots, N$ that satisfies the Bellman equations (8) and (9), the match formation conditions (10) and the laws of motion (1) and (2).

Notice the similarity between the equilibrium conditions and the planner's optimality conditions. Comparing (10) and (3) we see that the competitive matching equilibrium shares a key feature with the social optimum: match formation is privately efficient. That is, under the bargaining procedure we proposed, for given values of $\lambda_{i}^{c}$ 's, the individual agents' utility maximizing matching decisions imply that a new match is formed only in the cases when doing so is efficient from the point of view of all the agents involved in the meeting. ${ }^{17}$

\footnotetext{
${ }^{17}$ In contrast, the surplus splitting rule in Diamond and Maskin $(1979,1981)$ implies that match creation and destruction is privately inefficient in the absence of exogenous government policy. To understand their result, consider a simple special case of the double breach illustrated in Figure 3, where $C$ and $D$ are also in a match of type $i$, so the situation between $B$ and $C$ is symmetric. Diamond and Maskin propose that $B$ and $C$ split their matching rents by solving $\max _{s}\left(V_{k}-s-V_{i}\right)\left(V_{k}+s-V_{i}\right)$. Clearly, symmetry implies that $s=0$ and that their respective gains from matching equal $V_{k}-V_{i}$. Therefore, they will choose to leave their partners to form a new match if $V_{k}-V_{i}>0$. Note that their decision to match generates $2 V_{k}+2 V_{0}$ and destroys $4 V_{i}$. So, there will be instances - specifically, those where $V_{k}+V_{0}-2 V_{i}<0$-in which $B$ and $C$ "leave money on the table" from the point of view of the four agents involved in the meeting: There is too much breach in the equilibrium where agents are free to walk away from their partners. Diamond and Maskin point out that private efficiency can be restored if agents are forced to pay what lawyers call "compensatory damages"; i.e., if in order to separate from their current partners, $B$ and $C$ are required to pay each of them $T=V_{i}-V_{0}$. Rents are now split by solving $\max _{s}\left(V_{k}-s-V_{i}-T\right)\left(V_{k}+s-V_{i}-T\right)$, so the respective gains to $B$ and $C$ if they match equal $V_{k}+V_{0}-2 V_{i}$. The payment of compensatory damages forces $B$ and $C$ to internalize the effect that their match-formation decisions have on their current partners, and consequently the decentralized equilibrium with this policy generates privately efficient separations. In our bilateral bargaining procedure, the outside option of $B$ (and $C$ ) reflects what $A$ (and $D$ ) is willing to pay, at most $2 V_{i}-V_{0}$ (instead of $V_{i}$ ), and thus our competitive matching equilibrium implements privately efficient separations without the need for government policy.
} 
The equilibrium values of the match to the pair satisfy very similar conditions to the ones that the shadow prices of the match must satisfy in a social optimum. In fact, conditions (8) and (9) would be identical to (4) and (5), were it not for the fact that in the optimality conditions there is a "2" in front of the contact rate $\alpha$. This difference is due to a search (or match-formation) externality: in the decentralized economy, an individual agent does not take into account the impact that her decisions to form and destroy matches have on the arrival of opportunities of the other agents. Although the arrival rate of any new opportunity is constant here, the arrival rate of a new opportunity with a particular type of agent is proportional to the measure of agents of that type. Also, whether or not a new match is formed depends not only on the quality of the new potential match, but also on the types of the existing matches. Therefore, the relevant meeting rate is quadratic, because the total number of contacts between type $i$ agents and type $j$ agents is equal to $\alpha n_{i} n_{j} .{ }^{18}$

The relationship between the equilibrium match values and the planner's shadow prices can also be recast as follows. Define $\mu_{i}=\lambda_{i}-\lambda_{0}$ and $\mu_{i}^{c}=\lambda_{i}^{c}-\lambda_{0}^{c}$. Then from (4), (5), (8) and (9), we have:

$$
\begin{aligned}
(r+\delta) \mu_{i}-\dot{\mu}_{i} & =2 y_{i}+2 \alpha \sum_{j=0}^{N} \sum_{k=1}^{N} n_{j} \pi_{k} \max _{\tau_{i j}^{k}, \tau_{0 j}^{k}}\left[\tau_{i j}^{k}\left(\mu_{k}-\mu_{i}-\mu_{j}\right)-\tau_{0 j}^{k}\left(\mu_{k}-\mu_{j}\right)\right] \\
2(r+\delta) \mu_{i}^{c}-2 \dot{\mu}_{i}^{c} & =4 y_{i}+2 \alpha \sum_{j=0}^{N} \sum_{k=1}^{N} n_{j} \pi_{k} \max _{\phi_{i j}^{k}, \phi_{0 j}^{k}}\left[\phi_{i j}^{k}\left(\mu_{k}^{c}-\mu_{i}^{c}-\mu_{j}^{c}\right)-\phi_{0 j}^{k}\left(\mu_{k}^{c}-\mu_{j}^{c}\right)\right] .
\end{aligned}
$$

Observe that if we modify the planner's problem by replacing $r$ in (11) with $r^{\prime}=2 r+\delta$, then the first order conditions of this modified planner's problem are identical to the equilibrium conditions for the competitive matching equilibrium in the steady state $\left(\dot{\mu}_{i}=\dot{\mu}_{i}^{c}=0\right)$, except that the flow outputs $y_{i}$ all appear multiplied by half for the planner. But a proportional change of all output levels $y_{i}$ just induces a proportional change in the paths of the $\mu_{i}$ 's that

\footnotetext{
${ }^{18}$ Mortensen (1982) shows that "mating models" in which an agent's decisions affect other agents' meeting probabilities typically fail to achieve the socially optimal allocation due to a search externality. This search externality may be avoided in an environment with "directed search," in which workers in matches of productivity $y_{i}$ look for employers who are in matches of productivity $y_{j}$, in the designated " $i-j$ island" (e.g., see Felli and Roberts (2001)). However, we consider the random search framework to be more suitable for our economy, where every worker and every employer is ex ante homogeneous and productivity differences are match-specific.
} 
solve (11), which does not change the choices of $\left\{\tau_{i j}^{k}, \tau_{0 j}^{k}\right\}$ nor the resulting distribution $\left\{n_{i}\right\}_{i=1}^{N}$. We summarize this result as follows:

Proposition 2 A competitive matching equilibrium exists. Moreover, all steady-state competitive matching equilibria satisfy the first order conditions of a modified social planner's problem, in which the subjective discount rate, $r$, is replaced by the higher rate $r^{\prime}=2 r+\delta$, where $\delta$ is the exogenous destruction rate of any match. The allocation that solves the modified planner's problem can be decentralized as a competitive matching equilibrium.

\section{Employment Protection}

In this section we introduce employment protection policies and characterize their effects on the equilibrium allocations and payoffs. The class of policies we consider specifies that when an employer breaks a match of type $i$, she must pay severance compensation $S_{i} \leq V_{i}-V_{0}$ to the worker she separates from, and a firing tax $T_{i}$ to the government. ${ }^{19}$ Note that the policies apply to separations initiated by employers ("dismissals") but not to those initiated by workers ("quits") and therefore break the symmetry between employers and workers. For this reason we now let $V_{i}$ be the value of a worker, $J_{i}$ the value of an employer, and $M_{i}=J_{i}+V_{i}$ the value of a match of type $i$ in the equilibrium. Because the employer and the worker in a match are no longer symmetric, we think of the matched pair without an outside production opportunity as being involved in continual negotiations, instead of simply splitting the output equally. Proposition 3, which we prove in the appendix, summarizes the effects that employment protection policies have on the outcomes of the different bargaining situations.

Proposition 3 (a) An unmatched employer and an unemployed worker who draw a new production opportunity $y_{k}$ always choose to match, and the expected gain to each equals $\frac{1}{2}\left(M_{k}-M_{0}\right)$. (b) A worker in a match of quality $i$ and an unmatched employer who draw a new production

\footnotetext{
${ }^{19}$ In what follows, we will skirt the issue of exactly how a government may be able to collect taxes from agents in a random-matching economy, as well as why the same government is unable to facilitate the matching process.
} 
opportunity $y_{k}$ choose to form the new match iff $M_{k}>M_{i}$. The expected gains to the worker and the new employer equal $\frac{1}{2} \max \left(M_{k}-M_{0}-S_{i}, 0\right)$ and $\frac{1}{2} \max \left(M_{k}-M_{i}, 0\right)$, respectively. The old employer's capital gain equals $-\frac{1}{2}\left\{\max \left[\min \left(M_{k}, M_{i}\right)-M_{0}-S_{i}, 0\right]\right\}$.

(c) An employer in a match of quality $i$ and an unemployed worker who draw a new production opportunity $y_{k}$ choose to form the new match iff $M_{k}^{\prime} \equiv M_{k}-T_{i}>M_{i}$. The expected gains to the employer and the new worker equal $\frac{1}{2} \max \left(M_{k}^{\prime}-M_{0}-S_{i}, 0\right)$ and $\frac{1}{2} \max \left(M_{k}^{\prime}-M_{i}, 0\right)$, respectively. The old worker's capital gain equals $-\frac{1}{2}\left\{\max \left[\min \left(M_{k}^{\prime}, M_{i}\right)-M_{0}-S_{i}, 0\right]\right\}$.

(d) An employer in a match of quality $i$ and a worker in a match of quality $j$ who draw a new production opportunity $y_{k}$ choose to form the new match iff $M_{k}^{\prime}+M_{0}>M_{i}+M_{j}$. The expected gains to the employer and the worker with the new matching opportunity equal $\frac{1}{2} \max \left(M_{k}^{\prime}-M_{j}-S_{i}, 0\right)$ and $\frac{1}{2} \max \left(M_{k}^{\prime}-M_{i}-S_{j}, 0\right)$, respectively. The expected gains to the old employer and the old worker are $-\frac{1}{2}\left\{\max \left[\min \left(M_{k}^{\prime}-M_{i}, M_{j}-M_{0}\right)-S_{j}, 0\right]\right\}$ and $-\frac{1}{2}\left\{\max \left[\min \left(M_{k}^{\prime}-M_{j}, M_{i}-M_{0}\right)-S_{i}, 0\right]\right\}$.

For given value functions, imposing firing taxes $T_{i}$ on employers tends to make existing matches more stable. The reason is that individual creation and destruction decisions depend on the sum of the payoffs of all the agents involved in a meeting. Forcing employers to pay firing taxes to an outside party reduces the total surplus associated with double breaches and employer-initiated single breaches, so both become less likely. As another corollary to Proposition 3, note that - as one might expect from the Coase Theorem-forcing employers to make severance payments $S_{i}$ to a worker upon dismissal has no effect on the match creation and destruction decisions, given the value functions. More subtle is the effect that these policies may have on the value functions themselves, which we turn to next.

Lemma 1 In an equilibrium with employment protection policies, the value of a match of 
quality $i=1, \ldots, N$ satisfies

$$
\begin{aligned}
r M_{i}-\dot{M}_{i}= & 2 y_{i}-\delta\left(M_{i}-M_{0}\right)+\alpha n_{0} \sum_{k=1}^{N} \pi_{k} \max _{\phi_{i 0}^{k}, \phi_{0 i}^{k}}\left(\phi_{i 0}^{k} \frac{M_{k}-M_{i}}{2}+\phi_{0 i}^{k} \frac{M_{k}-M_{i}-T_{i}}{2}\right) \\
& +\alpha \sum_{j=1}^{N} \sum_{k=1}^{N} n_{j} \pi_{k} \max _{\phi_{i j}^{k}, \phi_{j i}^{k}}\left(\phi_{i j}^{k} \frac{M_{k}+M_{0}-M_{i}-M_{j}-T_{j}}{2}+\phi_{j i}^{k} \frac{M_{k}+M_{0}-M_{i}-M_{j}-T_{i}}{2}\right),
\end{aligned}
$$

and the sum of the values of an unmatched employer and an unemployed worker satisfies

$$
r M_{0}-\dot{M}_{0}=\alpha n_{0} \sum_{k=1}^{N} \pi_{k}\left(M_{k}-M_{0}\right)+\alpha \sum_{j=1}^{N} \sum_{k=1}^{N} n_{j} \pi_{k} \max _{\phi_{0 j}^{k}, \phi_{j 0}^{k}}\left(\phi_{0 j}^{k} \frac{M_{k}-M_{j}-T_{j}}{2}+\phi_{j 0}^{k} \frac{M_{k}-M_{j}}{2}\right) .
$$

(Lemma 1 is proved in the appendix.) Note that if we set $T_{i}=0$ for all $i,(13)$ and (14) reduce to (8) and (9), and the break-up conditions in Proposition 3 are equivalent to (10). Interestingly, the value functions are always independent of severance pay, $S_{i}$. Thus, severance pay is neutral: it has no effect on the equilibrium allocations or the value of the match (even if it affects the way the worker and the employer split that value). ${ }^{20}$

\section{$5 \quad$ Free Entry}

So far we have been assuming constant and equal populations of employers and workers. In this section we generalize the formulation by allowing free entry of employers. (The results corresponding to the alternative formulation with fixed and different population sizes will be obtained as a special case.) Let $m_{j}$ be the number of employers in matches of productivity $y_{j}$. We still use $n_{i}$ to denote number of workers employed in matches of productivity $y_{i}$. Since matching is one-to-one, $m_{i}=n_{i}$ for all $i \geq 1$, but $m_{0}$ (the number of unmatched employers) may be larger or smaller than $n_{0}$ (the number of unemployed workers). We assume that a worker contacts an employer who is currently in a match of type $j$ at rate $\alpha m_{j}$, while an employer

\footnotetext{
${ }^{20}$ The idea that government-mandated transfers between the employer and the worker can be offset by private contracts between the parties goes back to Lazear (1990). Lazear also notes that severance pay effects are neutral only when the payment made by the employer is received by the worker, and not if third-party intermediaries receive or make any of the payments.
} 
contacts a random worker in a match of type $i$ at rate $\alpha n_{i}{ }^{21}$ We also assume that unmatched employers incur a total flow cost $C\left(m_{0}\right)$ of posting vacancies, with $C^{\prime} \geq 0$ and $C^{\prime \prime}>0$ and $C^{\prime}(0)=0$.

We begin by solving the planner's problem. The planner chooses $\tau_{i j}^{k} \in[0,1]$ and $m_{0} \geq 0$ to maximize the discounted value of aggregate output

$$
\int e^{-r t}\left[\sum_{i=1}^{N} 2 y_{i} n_{i}-C\left(m_{0}\right)\right] d t
$$

subject to the flow constraints

$$
\begin{aligned}
& \dot{n}_{i}=\alpha \pi_{i} \sum_{j=0}^{N} \sum_{k=0}^{N} n_{j} m_{k} \tau_{j k}^{i}-\alpha n_{i} \sum_{j=0}^{N} \sum_{k=1}^{N} m_{j} \pi_{k} \tau_{i j}^{k}-\alpha m_{i} \sum_{j=0}^{N} \sum_{k=1}^{N} n_{j} \pi_{k} \tau_{j i}^{k}-\delta n_{i}, \\
& \dot{n}_{0}=\alpha \sum_{i=0}^{N} \sum_{j=1}^{N} \sum_{k=1}^{N} n_{i} m_{j} \pi_{k} \tau_{i j}^{k}+\delta \sum_{j=1}^{N} n_{j}-\alpha n_{0} \sum_{j=0}^{N} \sum_{k=1}^{N} m_{j} \pi_{k} \tau_{0 j}^{k},
\end{aligned}
$$

and initial conditions for $n_{i}, i=0, \ldots, N$. Let $\lambda_{i}$ be the shadow price of a match with productivity $y_{i}$ at date $t$. The Hamiltonian is

$$
H=\sum_{i=1}^{N} 2 y_{i} n_{i}-C\left(m_{0}\right)-\delta \sum_{i=1}^{N} n_{i}\left(\lambda_{i}-\lambda_{0}\right)+\alpha \sum_{i=0}^{N} \sum_{j=0}^{N} \sum_{k=1}^{N} n_{i} m_{j} \pi_{k} \tau_{i j}^{k}\left(\lambda_{k}+\lambda_{0}-\lambda_{i}-\lambda_{j}\right) .
$$

The optimality conditions for $\tau_{i j}^{k}$ are still given by (3), while the choice of $m_{0}$ satisfies

$$
C^{\prime}\left(m_{0}\right)=\alpha \sum_{i=0}^{N} \sum_{k=1}^{N} n_{i} \pi_{k} \tau_{i 0}^{k}\left(\lambda_{k}-\lambda_{i}\right)
$$

The left-hand side of condition (17) is the marginal cost of an unmatched employer (or the marginal cost of "maintaining a vacancy"), and the right side is the expected return from having an additional unmatched employer $\left(\lambda_{k}-\lambda_{i}\right.$ is the capital gain to the planner from creating a new match of productivity $y_{k}$ by matching an unmatched employer to a worker employed in a match of productivity $y_{i}$, while $\alpha n_{i} \pi_{k} \tau_{i 0}^{k}$ is the arrival rate of this capital gain).

\footnotetext{
${ }^{21}$ In other words, the total number of meetings is given by a quadratic matching technology, $\alpha m n$, where $m$ is the total number of employers and $n$ the total number of workers. In our formulation, $n=1$ and $m=1-n_{0}+m_{0}$. In the Appendix we also work out the optimality conditions for the case in which the aggregate meeting technology is instead given by a function $\xi(m, n)$ which is monotonic in both arguments and homogeneous of degree one.
} 
The Euler equations are:

$$
\begin{aligned}
r \lambda_{i}-\dot{\lambda}_{i}= & 2 y_{i}-\delta\left(\lambda_{i}-\lambda_{0}\right)+\alpha m_{0} \sum_{k=1}^{N} \pi_{k} \tau_{i 0}^{k}\left(\lambda_{k}-\lambda_{i}\right)+\alpha n_{0} \sum_{k=1}^{N} \pi_{k} \tau_{0 i}^{k}\left(\lambda_{k}-\lambda_{i}\right) \\
& +\alpha \sum_{j=1}^{N} \sum_{k=1}^{N} n_{j} \pi_{k}\left(\tau_{i j}^{k}+\tau_{j i}^{k}\right)\left(\lambda_{k}+\lambda_{0}-\lambda_{i}-\lambda_{j}\right),
\end{aligned}
$$

for $i=1, \ldots, N$, and

$$
r \lambda_{0}-\dot{\lambda}_{0}=\alpha m_{0} \sum_{k=1}^{N} \pi_{k} \tau_{00}^{k}\left(\lambda_{k}-\lambda_{0}\right)+\alpha \sum_{j=1}^{N} \sum_{k=1}^{N} n_{j} \pi_{k} \tau_{0 j}^{k}\left(\lambda_{k}-\lambda_{j}\right) .
$$

We can use the optimality conditions (3) and (17) to rewrite the Euler equations:

$$
\begin{aligned}
r \lambda_{i}-\dot{\lambda}_{i}= & 2 y_{i}-\delta\left(\lambda_{i}-\lambda_{0}\right)+\alpha\left(m_{0}+n_{0}\right) \sum_{k=1}^{N} \pi_{k} \max _{\tau_{i 0}^{k}} \tau_{i 0}^{k}\left(\lambda_{k}-\lambda_{i}\right) \\
& +2 \alpha \sum_{j=1}^{N} \sum_{k=1}^{N} n_{j} \pi_{k} \max _{\tau_{i j}^{k}} \tau_{i j}^{k}\left(\lambda_{k}+\lambda_{0}-\lambda_{i}-\lambda_{j}\right) \\
r \lambda_{0}-\dot{\lambda}_{0}= & -C^{\prime}\left(m_{0}\right)+\alpha\left(m_{0}+n_{0}\right) \sum_{k=1}^{N} \pi_{k} \max _{\tau_{00}^{k}} \tau_{00}^{k}\left(\lambda_{k}-\lambda_{0}\right) \\
& +2 \alpha \sum_{j=1}^{N} \sum_{k=1}^{N} n_{j} \pi_{k} \max _{\tau_{0 j}^{k}} \tau_{0 j}^{k}\left(\lambda_{k}-\lambda_{j}\right) .
\end{aligned}
$$

Conditions (18) and (19) are very similar to those for the model with constant and equal populations of employers and workers. In particular, note that they reduce to (4) and (5) respectively if we set $C^{\prime}=0$ and $m_{0}=n_{0}$. Alternatively, we can set $C^{\prime}=0$ but treat the initial condition for $m_{0}$ parametrically, to obtain a formulation with fixed but not necessarily equal populations of employers and workers. In the model with free entry we have an additional unknown at each date, and (17) provides the additional optimality condition.

Next, we characterize the competitive matching equilibrium using the bargaining procedure we described in Section 3. Here, we also allow for the employment protection policies introduced in Section 4, and as in that section, we will let $V_{i}$ be the value of a worker, $J_{i}$ the value of an employer, and $M_{i}=J_{i}+V_{i}$ the value of a match of type $i$ in the equilibrium. Each employer 
who posts a vacancy pays $c=C^{\prime}\left(m_{0}\right)$, while filled employers do not have to pay anything (e.g., because production itself is free advertisement to attract workers). ${ }^{22}$ The equilibrium outcomes in the different types of bargaining situations are still described by Proposition 3.

As before, the choice of a worker in a match of type $i$ and an employer in a match of type $j$ to form a new match of type $k$ is represented by $\phi_{i j}^{k} \in[0,1]$. Given the outcomes of the bargaining procedure, we have:

Lemma 2 In an equilibrium with employment protection polices and possibly different population sizes of employers and workers, the value of a match of quality $i=1, \ldots, N$ satisfies

$$
\begin{aligned}
r M_{i}-\dot{M}_{i}= & 2 y_{i}-\delta\left(M_{i}-M_{0}\right)+\alpha \sum_{k=1}^{N} \pi_{k} \max _{\phi_{i 0}^{k}, \phi_{0 i}^{k}}\left(m_{0} \phi_{i 0}^{k} \frac{M_{k}-M_{i}}{2}+n_{0} \phi_{0 i}^{k} \frac{M_{k}-M_{i}-T_{i}}{2}\right) \\
& +\alpha \sum_{j=1}^{N} \sum_{k=1}^{N} n_{j} \pi_{k} \max _{\phi_{i j}^{k}, \phi_{j i}^{k}}\left(\phi_{i j}^{k} \frac{M_{k}+M_{0}-M_{i}-M_{j}-T_{j}}{2}+\phi_{j i}^{k} \frac{M_{k}+M_{0}-M_{i}-M_{j}-T_{i}}{2}\right),
\end{aligned}
$$

and the sum of the values of an unmatched employer and an unemployed worker satisfies

$$
\begin{aligned}
r M_{0}-\dot{M}_{0}= & -c+\alpha\left(m_{0}+n_{0}\right) \sum_{k=1}^{N} \pi_{k} \frac{M_{k}-M_{0}}{2} \\
& +\alpha \sum_{j=1}^{N} \sum_{k=1}^{N} n_{j} \pi_{k} \max _{\phi_{0 j}^{k}, \phi_{j 0}^{k}}\left(\phi_{0 j}^{k} \frac{M_{k}-M_{j}-T_{j}}{2}+\phi_{j 0}^{k} \frac{M_{k}-M_{j}}{2}\right),
\end{aligned}
$$

where $c=C^{\prime}\left(m_{0}\right)$.

(Lemma 2 is proved in the appendix.) Since there is free entry of employers, any equilibrium with a positive measure of unmatched employers must be such that the expected return to an unmatched employer is just enough to cover the entry cost:

$$
c=\alpha \sum_{i=0}^{N} \sum_{k=1}^{N} n_{i} \pi_{k} \phi_{i 0}^{k} \frac{M_{k}-M_{i}}{2} .
$$

If we set $T_{i}=0$ for all $i$, and then compare (20), (21) and (22) with (18), (19) and (17), we see that - just as in the case with fixed and equal populations of employers and workersthe planner's first-order conditions and the equilibrium conditions in the steady state differ

\footnotetext{
${ }^{22}$ If $C\left(m_{0}\right)$ is strictly convex, profit $c m_{0}-C\left(m_{0}\right)$ is distributed to the owners of the scarce factor in the vacancy-posting technology. This profit will not affect the labor market because the utility function is linear.
} 
only in that in his calculations, the planner imputes an "effective" contact rate equal to $2 \alpha$ instead of just $\alpha$, the contact rate of an individual agent. So following the same logic that led to Proposition 2, if we replace the subjective discount rate of the social planner, $r$, with $r^{\prime}=2 r+\delta$, then again, in the steady state the first order conditions corresponding to the modified planner's problem correspond to ones of the competitive matching equilibria. And if the equilibrium is unique, then the equilibrium allocation is identical to that of the modified social planner's economy.

\section{Further Analysis and Labor Market Implications}

In this section we lay out a version of the model with two productivity levels $(N=2)$ and restrict our attention to the class of stationary equilibria. Our motivation is twofold. First, we want to illustrate some of the theoretical results derived in the previous sections, such as the inefficiency of the competitive matching equilibrium (Proposition 2). Second, we want to show how the theory relates to several strands of the macro-labor literature, and in particular how it can help conceptualize many of the empirical studies of gross job and worker flows.

We begin by considering the model of Section 3, where there is no government policy, and the numbers of employers and workers are fixed, equal, and normalized to unity. For this case, (1) and (2) reduce to

$$
\begin{aligned}
& \dot{n}_{2}=\alpha \pi\left(n_{0}^{2}+2 n_{0} n_{1}+n_{1}^{2} \phi\right)-\delta n_{2} \\
& \dot{n}_{1}=\alpha(1-\pi) n_{0}^{2}-2 \alpha \pi n_{0} n_{1}-2 \alpha \pi n_{1}^{2} \phi-\delta n_{1} \\
& \dot{n}_{0}=\delta\left(n_{1}+n_{2}\right)+\alpha \pi n_{1}^{2} \phi-\alpha n_{0}^{2} .
\end{aligned}
$$

As long as the value function is increasing in the productivity of the current match $\left(V_{0}<V_{1}<\right.$ $V_{2}$ ) - which will be the case - we know that $\phi_{0 j}^{2}=1$ for $j=0,1$ and that $\phi_{i 2}^{k}=0$ for all $i$ and $k$. Thus the only non-trivial choice occurs when a worker employed in a match of productivity $y_{1}$ meets an employer who is in a match of productivity $y_{1}$, and they draw an opportunity to produce $y_{2}$. To simplify notation, we let $\phi=\phi_{11}^{2}$ and $\pi=\pi_{2}\left(\right.$ so $\left.\pi_{1}=1-\pi\right)$. Figure 5 
illustrates the worker flows and Lemma 3 in the appendix establishes that a unique steady state distribution of workers exists for any given $\phi \in[0,1]$.

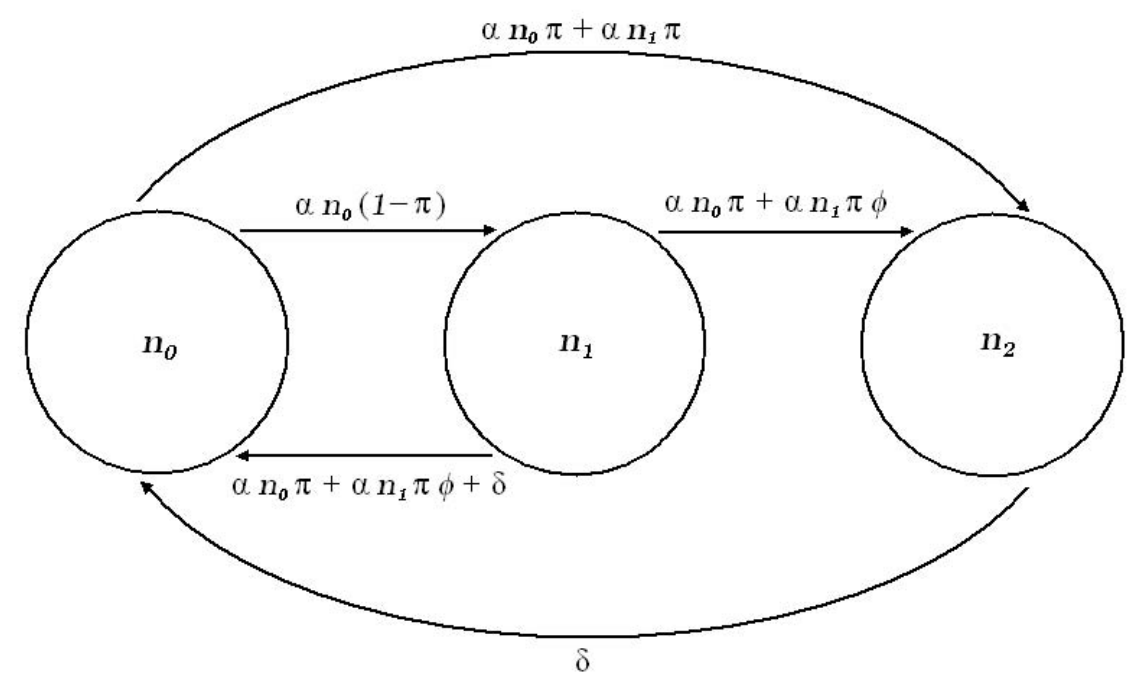

Figure 5: Worker flows for the case of $N=2$.

In a stationary equilibrium the value functions satisfy:

$$
\begin{aligned}
& r V_{2}=y_{2}-\delta\left(V_{2}-V_{0}\right) \\
& r V_{1}=y_{1}-\delta\left(V_{1}-V_{0}\right)+\alpha n_{0} \pi\left(V_{2}-V_{1}\right)+\alpha n_{1} \pi \phi\left(V_{2}+V_{0}-2 V_{1}\right) \\
& r V_{0}=\alpha n_{0}\left[\pi\left(V_{2}-V_{0}\right)+(1-\pi)\left(V_{1}-V_{0}\right)\right]+\alpha n_{1} \pi\left(V_{2}-V_{1}\right) .
\end{aligned}
$$

From Proposition 1 we know that $\phi=1$ with certainty if and only if $V_{2}+V_{0}-2 V_{1}>0$. We can use the Bellman equations to write this inequality as

$$
\frac{y_{2}}{y_{1}}>2-\frac{\alpha\left[\pi n_{1}+(1-\pi) n_{0}\right]}{r+\delta+\alpha\left(n_{0}+\pi n_{1}\right)}
$$

where $n_{0}$ and $n_{1}$ are the steady state numbers of matches, i.e., $n_{0}$ and $n_{1}$ satisfy (23)-(25) with $\dot{n}_{2}=\dot{n}_{1}=\dot{n}_{0}=0$ (see Lemma 3 for details). Since the right side of (26) is bounded, it is clear that $\phi=1$ with certainty for $y_{2} / y_{1}$ large enough. In these cases, the agents involved will destroy two middle-productivity matches in order to form a single high-productivity match whenever the 
opportunity arises. Perhaps more surprisingly, notice that there is always some $x>0$ such that $\phi=1$ for all $y_{2} / y_{1}>2-x$. That is, there is always a range of the productivity differential $y_{2} / y_{1}$ for which two middle-productivity matches are destroyed to form a single high-productivity match even if this entails a reduction in current output. To find a stationary equilibrium, let $n_{i}(\phi)$ denote the steady state number of matches of productivity $y_{i}$ as characterized in Lemma 3. Define the best-response map $\Phi(\phi)=\frac{y_{2}}{y_{1}}+\frac{\alpha\left[\pi n_{1}(\phi)+(1-\pi) n_{0}(\phi)\right]}{r+\delta+\alpha\left[n_{0}(\phi)+\pi n_{1}(\phi)\right]}-2$. From this we see that $\phi=1$ is an equilibrium if $\Phi(1)>0, \phi=0$ is an equilibrium if $\Phi(0)<0$, and $\phi^{*} \in[0,1]$ is an equilibrium if $\Phi\left(\phi^{*}\right)=0$. The map $\Phi$ is continuous on $[0,1]$, so there always exists a stationary equilibrium. However, an equilibrium is not always unique, leading to the possibility of coordination failure. ${ }^{23}$

Given (26), Proposition 2 tells us that the social planner chooses to destroy a pair of matches of productivity $y_{1}$ to create a single match of productivity $y_{2}$ if and only if

$$
\frac{y_{2}}{y_{1}}>2-\frac{2 \alpha\left[\pi n_{1}+(1-\pi) n_{0}\right]}{r+\delta+2 \alpha\left(n_{0}+\pi n_{1}\right)}
$$

with $n_{0}$ and $n_{1}$ again given by Lemma 3 . Notice that here there also are instances in which the planner chooses to destroy two matches of productivity $y_{1}$ to create a single match of productivity $y_{2}$ at the cost of reducing current output. From a static point of view, this may come as a surprise, since unmatched agents are unproductive; but from the planner's dynamic perspective, unmatched agents are a valued input in the matching process because the unmatched pair helps other agents climb the productivity ladder. Hence, for some parametrizations (e.g., $y_{2} / y_{1}$ slightly below 2), the planner may choose to reduce current output as a form of investment, in order to increase future output with a larger number of high productivity matches. This intuition can be formalized by noticing that the right-hand side of (27) approaches 2 as $r$ becomes large. The higher the degree of impatience, the less willing the planner is to trade off current for future production.

\footnotetext{
${ }^{23}$ The coordination failure may arise here, because the matching technology is effectively quadratic, and exhibits increasing returns-to-scale. See Diamond (1982b) and Mortensen (1989) for more on this type of coordination failure. We can show that $\pi \geq \frac{1}{3}$ is a sufficient condition for the uniqueness of the steady state competitive equilibrium with $N=2$. In what follows, we continue the discussion for the case of unique equilibrium.
} 
From (26) and (27) we also learn that failing to internalize the search externality makes atomistic agents less willing to destroy middle matches relative to the planner. To understand why this is the case, recall that from Proposition 2 we know that the competitive matching equilibrium corresponds to a modified planner's economy with a higher discount rate $r^{\prime}=2 r+\delta$. Thus the modified planner is less willing to trade off current for future output. Consequently, the modified planner is (agents in the competitive matching equilibrium are) less willing to trade two matches of productivity $y_{1}$ for two agents in a match of productivity $y_{2}$ and two unmatched agents.

Figure 6 illustrates the difference between the relevant destruction margins in the efficient and the competitive solutions. On the horizontal axis is $r$, the discount rate, and on the vertical axis $y_{2} / y_{1}$, the relevant measure of inequality in instantaneous productivities. Notice that the $\left(n_{0}, n_{1}\right)$ pair that appears in (26) is identical to that in $(27)$, both satisfy $(23)-(25)$ with $\dot{n}_{2}=\dot{n}_{1}=\dot{n}_{0}=0$, and are independent of $y_{1}, y_{2}$ and $r$. The solid lines with the higher and lower intercepts are conditions (26) and (27), respectively, at equality. As in the competitive economy, we know that for the social planner's economy $\tau_{0 j}^{2}=1$ for $j=0,1$, and that $\tau_{i 2}^{k}=0$ for all $i$ and $k$, and therefore we use $\tau$ to denote $\tau_{11}^{2}$, the only nontrivial decision. Double breaches occur in the competitive equilibrium only for parametrizations that lie above the higher solid line. In contrast, the planner implements double breaches for parametrizations that lie above the lower solid line. For any given degree of impatience $r$, the competitive and the efficient allocations coincide only if the flow productivity differential $y_{2} / y_{1}$ is either large enough (i.e., above the higher solid line) or small enough (below the lower solid line). For intermediate values the allocations differ relative to the efficient benchmark: matches of productivity $y_{1}$ are too stable in the competitive economy.

It is possible to design policies that bring the competitive allocation in line with the planner's. For example, suppose every agent receives a payoff $b>0$ while unmatched, and that this transfer is paid for by levying a tax $T_{e}$ from every matched agent. The balanced-budget 


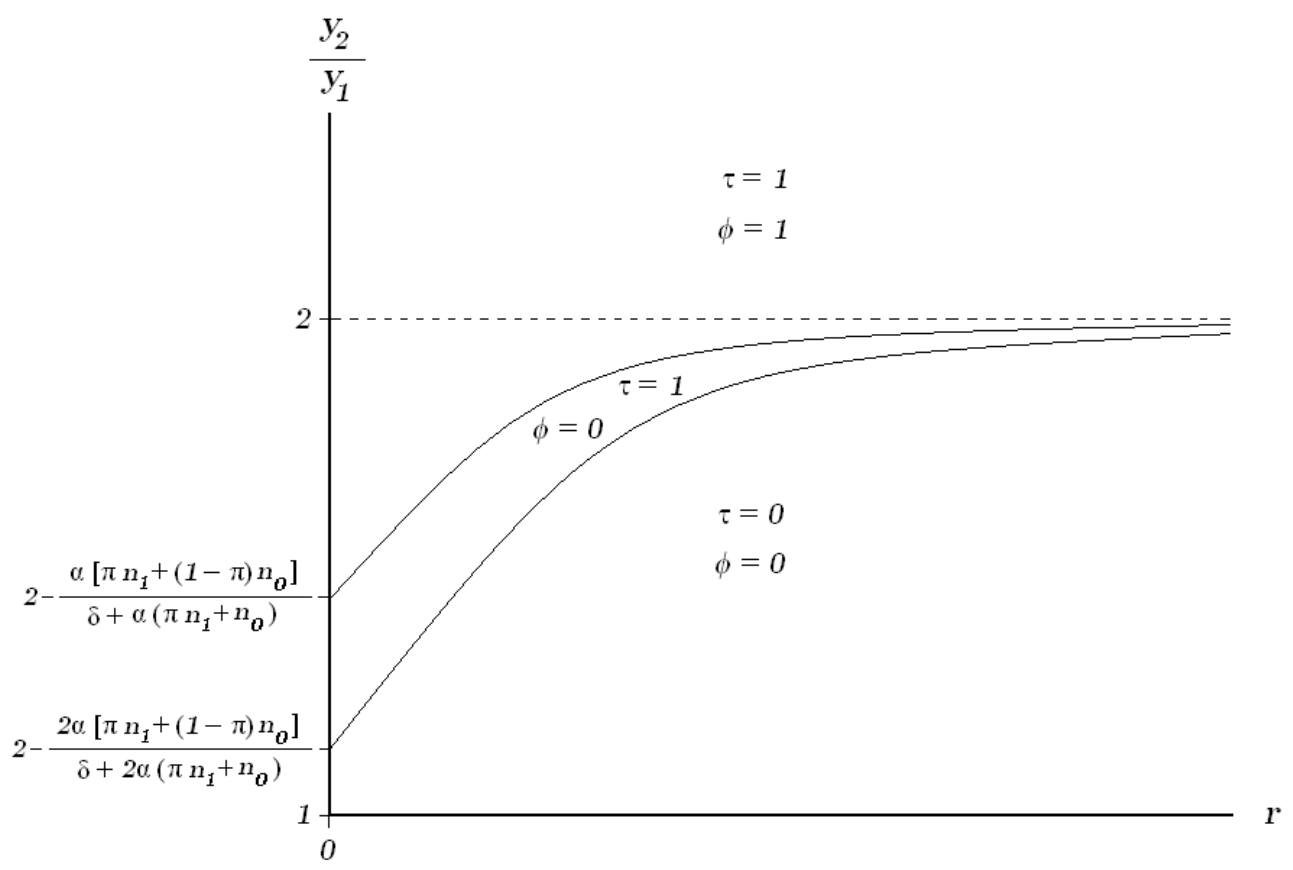

Figure 6: Destruction regions for the case with $N=2$.

condition is $b n_{0}=T_{e}\left(n_{1}+n_{2}\right)$. The Bellman equations for the competitive economy become

$$
\begin{aligned}
r \hat{V}_{2} & =y_{2}-T_{e}-\delta\left(\hat{V}_{2}-\hat{V}_{0}\right) \\
r \hat{V}_{1} & =y_{1}-T_{e}-\delta\left(\hat{V}_{1}-\hat{V}_{0}\right)+\alpha n_{0} \pi\left(\hat{V}_{2}-\hat{V}_{1}\right)+\alpha n_{1} \pi \phi\left(\hat{V}_{2}+\hat{V}_{0}-2 \hat{V}_{1}\right) \\
r \hat{V}_{0} & =b+\alpha n_{0}\left[\pi\left(\hat{V}_{2}-\hat{V}_{0}\right)+(1-\pi)\left(\hat{V}_{1}-\hat{V}_{0}\right)\right]+\alpha n_{1} \pi\left(\hat{V}_{2}-\hat{V}_{1}\right) .
\end{aligned}
$$

Notice that this policy can only affect the flow equations (23)-(25) indirectly through their effect on the separation decision $\phi$. So for a given $\phi$, the stationary distribution of agents across states is still described by Lemma 3 . However, now $\phi=1$ with certainty if and only if $\hat{V}_{2}+\hat{V}_{0}-2 \hat{V}_{1}>0$, which, using the government budget constraint, can be written as

$$
\frac{y_{2}-\frac{T_{e}}{n_{0}}}{y_{1}-\frac{T_{e}}{n_{0}}}>2-\frac{\alpha\left[\pi n_{1}+(1-\pi) n_{0}\right]}{r+\delta+\alpha\left(n_{0}+\pi n_{1}\right)} .
$$

Observe that if we let $T_{e}=T_{e}^{*}$, where

$$
T_{e}^{*}=\frac{\alpha n_{0}(r+\delta)\left[\pi n_{1}+(1-\pi) n_{0}\right]}{\left[r+\delta+2 \alpha\left(n_{0}+\pi n_{1}\right)\right]\left(r+\delta+\alpha \pi n_{0}\right)} y_{1},
$$


then (28) coincides with (27). In other words, the compensation $b^{*}=\frac{n_{1}+n_{2}}{n_{0}} T_{e}^{*}$ makes agents internalize the search externality in the competitive matching equilibrium and implements the planner's match creation and destruction decisions. ${ }^{24}$

To explore the effects of employment protection policies, we now turn to the more general formulation of Section 5. We introduce employment protection policies akin to the ones observed in many actual economies and allow for the number of unmatched employers $\left(m_{0}\right)$ to differ from the number of unemployed workers $\left(n_{0}\right)$. We now use $T$ to denote the firing tax that an employer who breaks a match must pay to the government. ${ }^{25}$ The laws of motion for the numbers of workers in each type of match are

$$
\begin{aligned}
& \dot{n}_{2}=\alpha \pi\left(m_{0} n_{0}+\psi n_{0} n_{1}+m_{0} n_{1}+\phi n_{1}^{2}\right)-\delta n_{2} \\
& \dot{n}_{1}=\alpha(1-\pi) m_{0} n_{0}-\delta n_{1}-\alpha \pi\left(\psi n_{0} n_{1}+m_{0} n_{1}+2 \phi n_{1}^{2}\right) \\
& \dot{n}_{0}=\alpha \pi \phi n_{1}^{2}+\delta\left(n_{1}+n_{2}\right)-\alpha m_{0} n_{0},
\end{aligned}
$$

where $\phi=\phi_{11}^{2}$ is the probability of a double breach, and $\psi=\phi_{01}^{2}$ denotes the probability that an employer in a low productivity match initiates a single breach. ${ }^{26}$ The values of a match to the pair in the stationary equilibrium satisfy:

$$
\begin{aligned}
& r M_{2}=2 y_{2}-\delta\left(M_{2}-M_{0}\right) \\
& r M_{1}=2 y_{1}-\delta\left(M_{1}-M_{0}\right)+\alpha \pi\left[m_{0} \frac{M_{2}-M_{1}}{2}+n_{0} \psi \frac{M_{2}-M_{1}-T}{2}+n_{1} \phi\left(M_{2}+M_{0}-2 M_{1}-T\right)\right] \\
& r M_{0}=-c+\alpha\left(m_{0}+n_{0}\right)\left[\pi \frac{M_{2}-M_{0}}{2}+(1-\pi) \frac{M_{1}-M_{0}}{2}\right]+\alpha n_{1} \pi\left[\psi \frac{M_{2}-M_{1}-T}{2}+\frac{M_{2}-M_{1}}{2}\right],
\end{aligned}
$$

where $c=C^{\prime}\left(m_{0}\right)$.

From Proposition 3 we know that $\psi=1$ if and only if $M_{2}-M_{1}-T>0$. Using the Bellman

\footnotetext{
${ }^{24}$ Here, the subsidy to the unmatched agents is beneficial because it internalizes search externalities and not because it provides insurance. A single subsidy and tax rate are enough to achieve the efficient allocation in this case with $N=2$, but this need not be the case with more heterogeneity of matches $(N>2)$.

${ }^{25}$ We do not specify any severance payments here, because they have no effect on match formation and destruction decisions, which is what we focus on hereafter.

${ }^{26}$ These are the only nontrivial decisions in this setting, since $\phi_{00}^{k}=1$ for $k=1,2, \phi_{10}^{2}=1$, and $\phi_{i j}^{k}=0$ if either $i \geq k$ or $j \geq k$.
} 
equations, we find that this inequality holds if and only if

$$
\frac{y_{2}}{y_{1}}>1+\frac{r+\delta+\frac{\alpha}{2} \pi m_{0}}{2 y_{1}} T
$$

Also, from Proposition 3 we know that $\phi=1$ if and only if $M_{2}+M_{0}-2 M_{1}-T>0$, and this inequality holds if and only if

$$
\frac{y_{2}-c}{y_{1}-c}>2-\frac{\alpha\left[\pi n_{1}+(1-\pi) \frac{m_{0}+n_{0}}{2}\right]}{r+\delta+\alpha\left(\frac{m_{0}+n_{0}}{2}+\pi n_{1}\right)}+\Omega T
$$

where

$$
\Omega \equiv \frac{(r+\delta)^{2}+(r+\delta) \frac{\alpha}{2}\left[m_{0}+n_{0}+\pi\left(m_{0}-n_{0}+n_{1}\right)\right]+\left(\frac{\alpha}{2}\right)^{2} \pi\left[\left(m_{0}+n_{0}\right)\left(m_{0}-\pi n_{0}\right)+\pi n_{1}\left(m_{0}-n_{0}\right)\right]}{2\left(y_{1}-c\right)\left[r+\delta+\frac{\alpha}{2}\left(m_{0}+n_{0}+2 \pi n_{1}\right)\right]} .
$$

Note that if we set $m_{0}=n_{0}$ and $c=T=0$, then (29) reduces to (26), the condition for double breaches to occur in the model with equal population sizes and no employment protection. Condition (29) is harder to satisfy for larger $T$ : higher firing taxes make double breaches less likely. In general, there will be two cutoffs, $T_{\phi}$ and $T_{\psi}$, with $T_{\phi}<T_{\psi}$, such that neither double breaches nor employer-initiated single breaches take place if $T>T_{\psi}$, single but no double breaches occur if $T_{\phi}<T<T_{\psi}$, and the match formation and destruction decisions are as in the model with no taxes if $T<T_{\phi}$.

The model has clear predictions regarding individual agents' employment histories, the various attributes of different types of jobs, and how they are affected by policy. For example, consider a job of productivity $y_{2}$ (a "good job") and another of productivity $y_{1}$ (a "bad job"). Then, good jobs are not only better paid, but also more stable. Good jobs are more stable than bad jobs in the sense that the expected time until a worker gets displaced is $\frac{1}{\delta}$ for the job of productivity $y_{2}$ and $\frac{1}{\delta+\alpha \pi\left(\psi n_{0}+\phi n_{1}\right)}$ for the job of productivity $y_{1} \cdot{ }^{27}$ Employment protection policies (e.g., $T>T_{\psi}$ ) could induce $\phi=\psi=0$ and render type 1 matches just as stable as type 2 matches. When displaced from a job of productivity $i$, the worker suffers a capital loss equal to $V_{i}-V_{0}$, and it will typically take him some time to climb back up to a job of productivity

\footnotetext{
${ }^{27}$ Instead of measuring how stable a match is in terms of the expected time it takes the worker to get fired, we could measure it in terms of the expected time it takes the worker to first find himself unemployed, which is $\frac{\delta+\alpha \pi\left(m_{0}+\phi n_{1}\right)}{\delta\left[\delta+\alpha \pi\left(m_{0}+\psi n_{0}+2 \phi n_{1}\right)\right]}$ for a worker in a match of productivity $y_{1}$ and $\frac{1}{\delta}$ for one in a match of productivity $y_{2}$.
} 
equal to or higher than the one he was displaced from. So the model is also consistent with the basic fact that displaced workers suffer significant and persistent income losses (see Jacobson et al. (1993) or Violante (2002)). ${ }^{28}$

As we mentioned earlier, there is a large body of empirical work that studies the properties of job and worker flows. One strand of this literature documents the sheer size of these flows, while another focuses on cross-country differences and tries to relate them to differences in labor market regulations. ${ }^{29}$ Our model can help organize many of the empirical findings. To illustrate, we first carry out in the theory, the same gross flows accounting exercises as Davis and Haltiwanger have pioneered with actual data.

Figure 7 displays the five types of transitions that an employer and a worker can find themselves in, and summarizes the basic calculations involved in computing the theoretical, "real-time" counterparts of the gross flows. ${ }^{30}$ Let $J C^{(t)}$ and $J D^{(t)}$ denote gross job creation and destruction over a period of length $t$. Then

$$
\begin{aligned}
J C^{(t)} & =\alpha\left(m_{0} n_{0}+\pi m_{0} n_{1}\right) t \\
J D^{(t)} & =\left[\alpha \pi\left(m_{0} n_{1}+\phi n_{1}^{2}\right)+\delta\left(n_{1}+n_{2}\right)\right] t
\end{aligned}
$$

and job reallocation is $J R^{(t)}=J C^{(t)}+J D^{(t)}$.

Let $H^{(t)}$ denote the number of hires, $L^{(t)}$ the number of layoffs (employer-initiated separations plus matches destroyed exogenously) and $Q^{(t)}$ the number of quits (worker-initiated

\footnotetext{
${ }^{28}$ For example, suppose a worker is displaced from a job of productivity $y_{1}$ (i.e., either his match is hit by the exogenous destruction shock $\delta$, or his employer fires him in order to form a new match of productivity $y_{2}$ with another worker). The expected time it takes this worker to find himself in a job that pays at least as well as the one he lost is $\frac{1}{\alpha\left(m_{0}+\pi \psi n_{1}\right)}$. And it takes a worker who gets displaced from a job of productivity $y_{2}$ even longer to see his income recover to the pre-displacement level; on average, precisely

$$
\frac{\delta+\alpha\left[(1-\pi) m_{0}+\pi \psi n_{0}+2 \pi \phi n_{1}\right]}{\alpha \pi\left\{\delta\left(m_{0}+\psi n_{1}\right)+\alpha\left[\pi\left(m_{0}+\psi n_{1}\right)\left(m_{0}+\psi n_{0}+2 \phi n_{1}\right)+(1-\pi)\left(m_{0}+\phi n_{1}\right) m_{0}\right]\right\}} .
$$

${ }^{29}$ The first strand stems from the work of Davis and Haltiwanger (1992), while examples of the second include Millard and Mortensen (1997), Bertola and Rogerson (1997), Ljungqvist and Sargent (1998), Mortensen and Pissarides (1999), Blanchard and Portugal (2001), and Pries and Rogerson (2005).

${ }^{30}$ The actual data used to construct the empirical job flows are collected rather infrequently, usually quarterly. Since our model economy is set in continuous time, we can compute all flows in "real time." We do this first, and address the issue of time-aggregation below. Also, empirical flows are usually normalized by a measure of the average employment level, but we omit this normalization to simplify the exposition.
} 


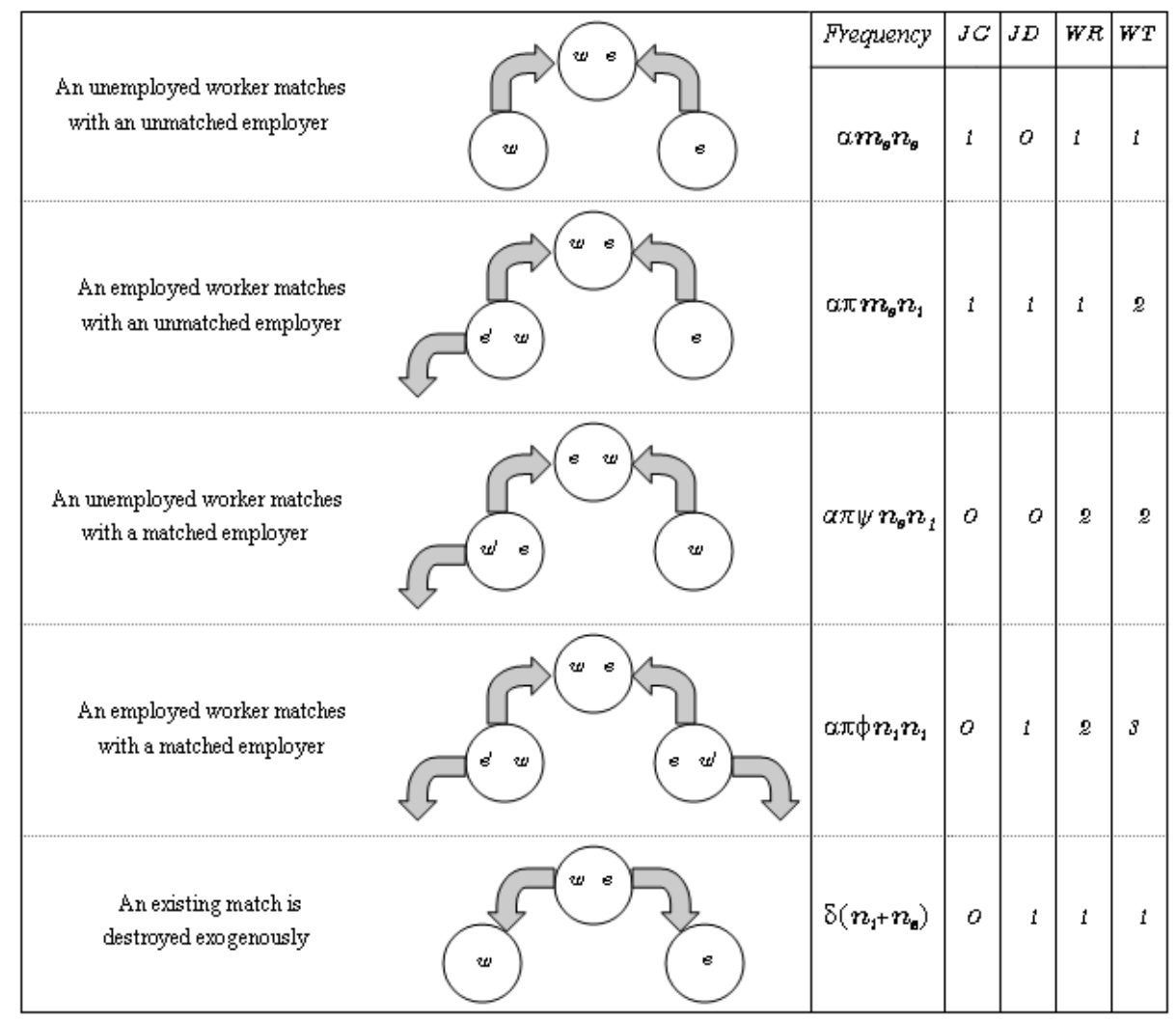

Figure 7: Job and worker flows accounting.

separations) that occur over a period of length $t$. We have

$$
\begin{aligned}
H^{(t)} & =\alpha\left[m_{0} n_{0}+\pi\left(m_{0} n_{1}+\psi n_{1} n_{0}+\phi n_{1}^{2}\right)\right] t \\
L^{(t)} & =\left[\alpha \pi\left(\psi n_{1} n_{0}+\phi n_{1}^{2}\right)+\delta\left(n_{1}+n_{2}\right)\right] t \\
Q^{(t)} & =\alpha \pi\left(m_{0} n_{1}+\phi n_{1}^{2}\right) t
\end{aligned}
$$

and total separations are $S^{(t)}=L^{(t)}+Q^{(t)}$. The empirical studies typically focus on worker turnover, $W T^{(t)}=H^{(t)}+S^{(t)}$, or on worker reallocation, $W R^{(t)}$, as measures of gross worker flows. According to the theory,

$$
W R^{(t)}=\alpha\left[m_{0} n_{0}+\pi\left(m_{0} n_{1}+2 \psi n_{1} n_{0}+2 \phi n_{1}^{2}\right)+\delta\left(n_{1}+n_{2}\right)\right] t .
$$

In the model, workers only quit to take better jobs, so the number of job-to-job transitions 
over a period of length $t$ is $J J^{(t)}=Q^{(t)}$. Since employers can also search while matched, they can make "worker-to-worker" transitions, the natural counterpart to the workers' job-to-job transitions. In fact, as we discussed in the introduction, the available evidence indicates that those types of transitions, often referred to as "replacement hiring" in the empirical literature, are actually quite prevalent in actual economies. In the model, replacement hiring in the aggregate, over a period of length $t$, is

$$
R H^{(t)}=\alpha \pi n_{1}\left(\psi n_{0}+\phi n_{1}\right) t
$$

Intuitively, $R H^{(t)}$ conveys how frequently employers churn their workers, while $J J^{(t)}$ is a measure of how frequently workers churn their employers. ${ }^{31}$

Having exact theoretical counterparts to all the empirical notions of job and worker flows makes it easier to appreciate the relationships between the different measures used in the literature. ${ }^{32}$ For example, job-to-job transitions account for the difference between worker turnover and worker reallocation: $W T^{(t)}-W R^{(t)}=J J^{(t)}$. Perhaps a more common measure of worker flows in excess of job flows is the difference between worker turnover and job reallocation (e.g., this is the notion of churning used by Burgess, Lane and Stevens (2000)):

$$
W T^{(t)}-J R^{(t)}=2 R H^{(t)}
$$

So in the model - as in the data - worker turnover is larger than gross job reallocation. ${ }^{33}$ Instances of replacement hiring lie behind this discrepancy, since job creation and destruction are unchanged when a firm fires a worker to replace him with an unemployed one, yet these events add two transitions (one for each worker involved) to the worker turnover count.

\footnotetext{
${ }^{31}$ In fact, $R H^{(t)}-J J^{(t)}=\alpha \pi n_{1}\left(\psi n_{0}-m_{0}\right) t$, so in general the difference depends on policy as well as on the relative numbers of unmatched employers and unemployed workers. For example, job-to-job transitions will exceed replacement hiring if $T>T_{\psi}$, and the magnitude of the difference is larger the greater the number of unmatched employers. Admittedly, capacity constraints are rather stark in our model (i.e., each employer can be matched with one worker), and perhaps overemphasize replacement hiring. We leave to future research the challenging - but potentially rewarding - analysis of a formulation with more general decreasing returns-to-scale.

${ }^{32}$ This is not a minor point. For example, Davis and Haltiwanger (1999, p. 82) point out that some studies have failed to appreciate the conceptual differences between gross worker reallocation and total turnover.

${ }^{33}$ See Davis and Haltiwanger (1992, 1999), Anderson and Meyer (1994), Hamermesh, Hassink and van Ours (1996), Davis, Haltiwanger and Schuh (1996), Albæk and Sørensen (1998), and Burgess, Lane and Stevens (2000).
} 
Some recent cross-country empirical studies have found that job reallocation turns out to be roughly similar across countries with very different labor market policies. Instead, the differences are in worker turnover. ${ }^{34}$ This seems to indicate that understanding the nature of worker turnover, and in particular, what determines worker turnover in excess of job reallocation, is key to understanding the role of policy in shaping labor market outcomes. Addressing these issues requires a theory that distinguishes between job and worker flows, a distinction which is absent from the bulk of the vast existing literature that uses matching models to assess the effects of labor market policy.

Combining (30) and (31) makes it clear how employment protection policies determine the amount of worker turnover in excess of job reallocation: for example, they will not differ much under very stringent regulations (e.g., $T$ close to $T_{\psi}$ ). As can be seen in Figure 7, employment protection policies hinder precisely the kinds of transitions that generate worker flows in excess of job flows (those in the third and fourth rows in the figure). Along these lines, Blanchard and Portugal (2001) find that relative to the United States, worker flows are smaller in Portugal even for given job flows. For instance, they estimate the flow of workers out of employment to be roughly between 1.5 and 2 times larger than job destruction in the United States, while in Portugal that flow barely exceeds job destruction. In our model, all workers exiting employment flow into unemployment; let $L^{(t)}$ denote these layoffs. We find $L^{(t)}-J D^{(t)}=R H^{(t)}-J J^{(t)}$. Policy affects this magnitude directly through its effects on the single breach decision $\psi$, and indirectly through its effect on the composition of the population, $m_{0}, n_{0}$, and $n_{1}$.

So far our theoretical accounting exercise has implicitly assumed access to real-time data. But many data are only available at a point in time, e.g., we know the employment level of a given establishment at dates $t$ and $t+1$, but have no information on what happened during the time interval $(t, t+1)$. Any attempt to measure employment-to-employment transitions, for

\footnotetext{
${ }^{34}$ Bertola and Rogerson (1997) were the first to note the fact that job reallocation rates do not vary much across countries with very different employment protection policies, such as Italy, Germany, France, the United Kingdom, and the United States. They also pointed out that average job tenures seem to be longer in regulated countries, suggesting that policy differences manifest themselves in worker turnover rates. See Pries and Rogerson (2005) for a summary of more recent evidence.
} 
instance, faces this time-aggregation problem and as a result may include as a single job-to-job transition an employer change, while there was an intervening period of nonemployment or even multiple employers between survey dates. There is usually no way of knowing the size or even the sign of this bias. ${ }^{35}$

In order to have an exact mapping between the accounting in the theory and that done for actual economies, next we will subject the theoretical accounting exercise to the same data limitations empirical researchers face. Lemma 4 in the appendix shows that the stochastic process that rules the evolution of a worker's state can be summarized by a matrix $\left[p_{i j}^{(t)}\right]$. For the simple case of $N=2$ the matrix is $3 \times 3$, and $p_{i j}^{(t)}$ represents the probability that the worker finds himself in state $j$ at date $t_{0}+t$ given that he was in state $i$ at date $t_{0}$. Arguments similar to those that lead to Lemma 4 can be used to show that the stochastic process that rules the evolution of an employer's state can be summarized by a matrix $\left[\hat{p}_{i j}^{(t)}\right]$, where $\hat{p}_{i j}^{(t)}$ represents the probability that an employer finds herself in state $j$ at date $t_{0}+t$, given she was in state $i$ at date $t_{0}$. With the matrices $\left[p_{i j}^{(t)}\right]$ and $\left[\hat{p}_{i j}^{(t)}\right]$ in hand, and given our economy is set in continuous time, we can compute any variable of interest and subject it to an arbitrary degree of timeaggregation. For example, suppose that a period of length $t$ elapses between worker surveys. Then, in the model, the time-aggregated number of job-to-job transitions is

$$
\overline{J J}^{(t)}=\left(p_{22}^{(t)}-e^{-\delta t}\right) n_{2}+\left(p_{11}^{(t)}-e^{-\left[\delta+\alpha \pi\left(m_{0}+\psi n_{0}+2 \phi n_{1}\right)\right] t}\right) n_{1}+p_{21}^{(t)} n_{2}+p_{12}^{(t)} n_{1},
$$

in contrast to the exact measure, $J J^{(t)}=\alpha \pi\left(m_{0} n_{1}+\phi n_{1}^{2}\right) t$. The first term on the right of (32) is the flow of workers who transit from a match of productivity $y_{2}$ to another match of productivity $y_{2}$ during a time interval of length $t$ (after subtracting those who never left the same match, with probability $e^{-\delta t}$ ). The second term is the similar worker flow from a match of productivity $y_{1}$ to another match of productivity $y_{1}$.

Now consider again the basic empirical finding that worker turnover is much larger than

\footnotetext{
${ }^{35}$ Fallick and Fleischman (2001), for example, explicitly acknowledge this problem and choose to classify all workers who report different employers in the two months they were surveyed as having had a (single) job-to-job transition.
} 
job reallocation. Since the former is calculated as the sum of all hires and separations over a given time interval, while job creation and job destruction are constructed from point-in-time employment data, one may wonder to what extent the amount of worker turnover in excess of job reallocation is a mere artifact of a time-aggregation bias. To answer this question, suppose employment data is only available at intervals of length $t$, and compute the timeaggregated theoretical measures of job creation, job destruction, and job reallocation: $\overline{J C}^{(t)}=$ $m_{0}\left[\hat{p}_{01}^{(t)}+\hat{p}_{02}^{(t)}\right], \overline{J D}^{(t)}=n_{1} \hat{p}_{10}^{(t)}+n_{2} \hat{p}_{20}^{(t)}$, and $\overline{J R}^{(t)}=\overline{J C}^{(t)}+\overline{J D}^{(t)}$. Using the theory, the difference between measured worker turnover and job reallocation can be written as

$$
W T^{(t)}-\overline{J R}^{(t)}=2 R H^{(t)}+\left[J R^{(t)}-\overline{J R}^{(t)}\right] .
$$

The amount of worker turnover in excess of what would be needed to accommodate the reallocation of jobs across establishments is composed of two parts, a "genuine" churning component, and another component which is purely due to a time-aggregation bias in job flows. A parametrized version of the model can be used to assess how the relative sizes of the genuine churning component and the component due to time-aggregation depend upon the data frequency, say monthly versus quarterly - another example of how the theory can serve as a guide to understanding the nature of job and worker flows. ${ }^{36}$

\section{$7 \quad$ Related Literature}

In this section we discuss how our paper relates to the existing literature on labor-market matching models with on-the-job search. Burdett (1978) adds on-the-job search to the single-agent

\footnotetext{
${ }^{36}$ To be clear, the empirical observation that worker flows exceed job flows at the establishment level is not, per se, unquestionable evidence supporting the empirical relevance of the employer-initiated separations in our theory. That is, the transitions that account for the excess worker turnover may not be exclusively due to the fact that, in order to hire a new worker with whom he has a more productive opportunity, the employer must fire an existing employee due to capacity constraints. In principle, the observation is also consistent with separations that occur for other reasons (e.g., as captured by the $\delta$-shock in the model) but are followed by a relatively quick replacement. Our view on this issue is that, from a theoretical standpoint, it is desirable to allow for the possibility that employers churn their workers (by engaging in replacement hiring), just as we allow workers to churn their employers (by engaging in job-to-job transitions). But also from an empirical standpoint, there are advantages to having a theory which exhibits both replacement hiring as well as separations followed by quick replacement. For one thing, as (33) suggests, such a theory can be used to extract more information from the available data in order to uncover what lies behind the excess worker reallocation at the micro level.
} 
search decision problem faced by a worker who samples wages from an exogenous distribution. Mortensen (1978) studies the relationship between the nature of the wage bargaining problem between a worker and an employer and their choices of on-the-job search intensities. He observes that the search intensities the employer and worker choose in a Nash equilibrium of the noncooperative game are too high relative to those that would be chosen jointly to maximize the value of the match. ${ }^{37}$

Diamond and Maskin (1979) extend Mortensen (1978) by embedding the search problem of the single partnership in an equilibrium model with many potential partnerships. They study the steady-state equilibria of a model in which agents are randomly paired in a costly search process to carry out a single productive project. As in our setup, agents are ex ante homogeneous, but matches are heterogeneous ex post and utility is transferable. The two key differences in our frameworks are that in that model (i) agents always split the match surplus symmetrically, and (ii) in anticipation of possible breaches, contracts may provide for compensation or "damages" to be paid to the breached-against partner, which requires that agents have the ability to commit to future actions or else that "courts" exogenously enforce these contracts. Diamond and Maskin show that if the partner who breaks the match is required to fully compensate the breached-against partner for the loss she suffers, then, as in our competitive matching equilibrium, the two individuals with the option to form a new match find it in their interest to breach precisely when by doing so they increase the sum of the expected payoffs of the four parties involved in the meeting. The difference is that our competitive matching equilibrium achieves this outcome through a more flexible bargaining process involving side payments, without requiring that agents be able to commit to compensate

\footnotetext{
${ }^{37}$ Mortensen explores the ability of two alternative mechanisms to improve efficiency when agents choose their search strategies noncooperatively. The mechanisms do not require direct monitoring, but rely on both agents' ability to commit to future actions. The first is an ex ante agreement by each partner to make a counteroffer when the other receives an attractive alternative matching opportunity. The second is an ex ante agreement to fully compensate the other partner as a precondition for separation. Relative to the joint wealth maximizing strategy, both partners search too much in the noncooperative Nash equilibrium under the mechanism with commitment to counteroffer. But under the commitment to fully compensate the partner in case of separation, the Nash noncooperative equilibrium delivers the pair of search strategies that maximize the joint surplus.
} 
their partners in case of future breaches. ${ }^{38}$

Wolinski (1987) also studies a matching model in which agents form bilateral relationships and can search for alternative partners while matched. The model builds on Diamond and Maskin (1979), but differs in that instead of assuming the axiomatic Nash solution, the surplus split between matched agents is determined by an explicit noncooperative bargaining game. In this sense, our work is similar to Wolinski's. However, the key difference between his work and ours is that he maintains the assumption that an agent cannot negotiate with two or more partners at the same time: upon meeting an alternative partner, a matched agent has to decide immediately whether to withdraw from his current match and form the new match or to reject the new opportunity to continue with the ongoing bargaining process.

The model in Burdett, Imai and Wright (2004) has ex ante homogeneous agents, ex post heterogeneous matches, costly search, and agents who, while matched, decide whether to search or not. They consider two setups. In the first setup, they assume that once two agents make contact, they cannot observe the realization of their prospective match productivity unless they drop their current partners (if they have any). ${ }^{39}$ Utility may be interpreted to be transferable or not in this setup. For this version of the model they provide a full characterization of the equilibrium set and its welfare properties. The second setup allows agents to keep the option to stay with their current partners after observing the realization of the match quality with a prospective partner. They lay out the model with two types of matches and argue that their main results (e.g., multiplicity and efficiency properties of equilibria) are robust to this

\footnotetext{
${ }^{38}$ In Diamond and Maskin (1979) agents match to produce once and for all. In some unpublished notes, Diamond and Maskin (1981) extend that framework to allow for continuous production. Their physical environment corresponds to the special case of our economy with $N=2$. In this version they continue to assume that partners split the matching surplus symmetrically and that when a partner separates, she must pay the breached-against partner compensatory damages, and explore some properties of a steady-state equilibrium in which single breaches occur but double breaches do not.

${ }^{39}$ This assumption makes their model extremely tractable by eliminating "composition effects": The gains from forming a match of a given quality are the same regardless of the state of the other partner, so the value functions are independent of the endogenous distribution of match qualities among actual relationships. The fact that payoffs depend on the distribution of characteristics of potential partners is a feature that arises naturally in our model and in many other matching models, both with ex post match heterogeneity and on-the-job search (e.g., Diamond and Maskin $(1979,1981)$ ) and with ex ante heterogeneity, even with no on-the-job search (e.g., Burdett and Coles (1997) and Shimer and Smith (2000, 2001)).
} 
generalization. This second setup relies on the assumption that utility is nontransferable. ${ }^{40}$ This must be so because if utility were transferable, then matched agents would attempt to counter their partners' outside offers just as they do in our model. So, although the physical environment of Burdett, Imai and Wright (2004) is close to ours, their analysis is quite different because they make assumptions that rule out the multilateral breach situations that are an essential part of our notion of equilibrium.

Burdett and Mortensen (1998) develop an influential on-the-job search model with ex ante homogeneous populations of employers and workers. ${ }^{41}$ Employers are assumed to post and commit to wages, have access to a constant returns-to-scale production technology, and may employ any number of workers at the posted wage. Whenever an employed worker meets an employer with a posted wage higher than her current wage, she quits to join the new employer's workforce. Therefore, employers who post low wages experience high quit rates and have smaller workforces in the steady state. By requiring that steady-state profit be equated across firms, Burdett and Mortensen derive a nondegenerate equilibrium wage distribution. Note that there is an extreme notion of commitment at work in this model: once the employer has chosen a wage to offer its employees, the assumption is that it cannot be changed. It cannot be raised to counter a worker's outside offer, and it cannot be cut down once the outside offer is gone.

Postel-Vinay and Robin (2002) work out an extension of Burdett and Mortensen (1998) with ex ante heterogeneous employers and workers. Employers still have the power to make take-it-or-leave-it offers to workers but are, in addition, allowed to counter the offers that their workers receive from competing employers. ${ }^{42}$ Relative to Burdett-Mortensen, the extension of

\footnotetext{
${ }^{40}$ The on-the-job search model of Cornelius (2003) also assumes utility is nontransferable, but differs from Burdett, Imai and Wright (2004) in that agents are ex ante heterogeneous, search is costless both on and off the job, and the meeting technology is quadratic.

${ }^{41}$ The Burdett-Mortensen model was originally developed to explain wage dispersion among homogeneous workers and relate it to employer size, but has by now been extended in many ways and applied to study a wide range of issues, both empirical and theoretical. Van den Berg and Ridder (1998) and Bontemps, Robin and van den Berg $(1999,2000)$ are examples of papers that have structurally estimated the model. Theoretical extensions and applications include Burdett and Coles (2003) and Burdett, Lagos and Wright (2004). See Manning (2003) and Mortensen (2003) for other applications and more references.

${ }^{42}$ Instead of giving the firm the power to make a worker take-it-or-leave-it offers, Dey and Flinn (2005) assume employers and workers in continuing relationships split the match surplus according to the Nash cooperative
} 
Postel-Vinay and Robin (2002) assumes a weaker form of commitment: Firms still commit not to reduce wages in the future, but can counter outside offers. In a different way, the extension of Coles (2001) also assumes a weaker form of commitment, this time by assuming firms cannot respond to outside offers but can change wages during times when their workforce has no outside offers outstanding. From this perspective, our paper differs from the literature in that neither employers nor workers can commit to any future actions.

Another relevant difference is that in the Burdett-Mortensen approach, each employer operates a constant returns-to-scale production technology that can, in principle, employ the whole population of workers. So if there are heterogeneous employers, it would be desirable - and technologically feasible - to have all workers matched to the highest-productivity employer. In contrast, we study the consequences of the opposite assumption to constant returns by assuming that each employer can hire at most one worker. This extreme version of decreasing returns enriches the sets of transitions that employers and workers can engage in, with no loss of tractability. For example, the model delivers endogenous "firing" in addition to endogenous "quits." Also, the limited-capacity assumption allows the model to exhibit instances of replacement hiring as well as situations in which - in the language of the empirical labor flows literature - job reallocation induces worker reallocation and vice versa.

In Pissarides (1994, 2000), employed workers can search on the job, but employers do not (so all quits involve workers taking jobs that were previously vacant), and the wage is assumed to be determined according to a linear surplus splitting rule at all times. Relative to what we do here, a key difference is that both in Pissarides (1994, 2000) and in Shimer (2004), matched employers are not allowed to offer side payments to counter their worker's outside offers, and similarly, a vacant employer who contacts an employed worker cannot make side payments to persuade the worker to quit. Competition involving side payments among all the parties involved in a typical on-the-job search meeting is an essential feature of the equilibrium in the model we develop here. Also, we propose a competitive bargaining procedure to split the gains solution. 
from trade instead of relying on surplus splitting rules or the Nash axiomatic approach. ${ }^{43}$

Our labor-market analysis in Section 6 was partly motivated by the evidence in Bertola and Rogerson (1997) and Blanchard and Portugal (2001), i.e., by the observation that worker turnover in Europe is substantially smaller than in the United States, whereas - despite the differences in labor-market policy regimes - job reallocation is roughly the same. With Blanchard and Portugal (2001) and Pries and Rogerson (2005) we share this observation as a motivation for developing a model that can help us understand the nature and the distinct allocative roles played by job flows and worker flows. Blanchard and Portugal (2001) argue that policies that increase unemployment durations decrease worker turnover by discouraging quits to unemployment. Pries and Rogerson (2005) develop a matching model that combines features of the Jovanovic (1979) learning model with the matching model of Pissarides (1985). ${ }^{44}$

In terms of distinguishing between job flows and worker flows, the key difference with Pries and Rogerson (2005) is that they abstract from on-the-job search for both employers and workers. For this reason, an employer who wishes to replace a worker is forced to become vacant before re-matching, and similarly, a worker is forced to go through unemployment in order to switch jobs. Thus, if an accountant were to survey this employer and this worker right after their separation, she would record an instance of job destruction as well as a transition toward the worker-turnover count. In other words, conceptually, that model is not able to distinguish between job and worker flows in real-time data. ${ }^{45}$ In contrast, in our continuoustime model where both employers and workers continue to search while matched, instances of replacement hiring will generate worker flows in excess of job flows in real time, even without time-aggregation in the job flows. We showed how theory can be used to measure which fraction

\footnotetext{
${ }^{43}$ Shimer (2004) points out that in the context of the on-the-job search model of Pissarides (1994, 2000), a simple linear surplus splitting rule is in general not equivalent to the Nash bargaining solution and that adopting the former may lead to pair-wise inefficient outcomes.

${ }^{44}$ In their model, when an employer and a worker meet, they observe a signal about the match's true quality prior to deciding whether to form the match, and matches are formed only if the signal exceeds a threshold value. The true quality of the match is revealed over time but through production, only if the match is formed. They then analyze how various labor-market regulations affect hiring through their effects on the threshold signal.

${ }^{45}$ Time-aggregation is the only reason why labor-market policies may affect job reallocation and worker turnover differently in that setup.
} 
of the worker flows in excess of job flows is due to workers churning over existing jobs, as opposed to the result of time-aggregation.

\section{Concluding Remarks}

We have developed a model of on-the-job search that has many of the stylized properties of actual labor markets. Worker flows exceed job flows, displaced agents suffer persistent reductions in permanent incomes, job-to-job transitions are common, and firms often engage in simultaneous hiring and firing. We have proposed and analyzed a notion of competitive equilibrium based on a particular bargaining procedure and explored its efficiency properties.

Several extensions seem worth pursuing. First, motivated by the observations in Bertola and Rogerson (1997) and Blanchard and Portugal (2001), the model could be used to quantify the effects that employment protection policies have on the amount of worker reallocation in excess of job reallocation. Bertola and Rogerson find that despite higher employment protection in Europe than in the United States, European job turnover rates are not that different from those in the United States, yet there is evidence that worker turnover is lower in Europe. Our model suggests a simple explanation for these observations: Employment protection policies censor precisely the transitions that cause worker turnover in excess of job turnover, namely, separations resulting from double breaches and from employer-initiated single breaches. ${ }^{46}$

A related issue is that, given the empirical relevance of job-to-job flows, an appropriate assessment of the welfare effects of employment protection policies calls for a model with onthe-job search, perhaps along the lines we have proposed here. Calculating the welfare effects of employment protection policies with a model that does not allow for job-to-job transitions is likely to understate the welfare losses from these policies, since they affect the overall efficiency of job-worker matches through their effects on worker flows in addition to their effects on job flows.

\footnotetext{
${ }^{46}$ This would complement the work of Pries and Rogerson (2005), who study this question from another angle, by focusing on the effect that labor market policies have on hiring practices.
} 
At a deeper level, we would also like to understand why employment protection policies exist. In our framework with one-employer-to-one-worker matching and transferable utility, workers and employers are inherently symmetric (even if allowing for free entry of employers or certain policies introduces a slight asymmetry), and employment protection policies result in no efficiency gains. To explore the rationale behind employment protection policies, perhaps we have to introduce some fundamental asymmetry, such as that each worker works for one employer while each employer hires several workers. This extension would also be useful to study issues related to the size distribution of firms, including the relationship between firm size and job and worker flows. 


\section{A Appendix}

\section{Bargaining outcomes and the core.}

Before proving part (c) of Proposition 1 we introduce some notation and define the core in our model. Let $I$ denote the set of agents who are directly or indirectly (i.e., through a partner) involved in a meeting. For example, $I=\{A, B, C, D\}$ in the situation illustrated in Figure 3. Within the context of a meeting, an allocation is a collection of partnerships. For example, there are two possible allocations for the meeting in Figure 3: $\langle(A, B),(C, D)\rangle$ and $\langle(B, C),(A, D)\rangle$. The first represents the case in which $A$ remains matched to $B$ while $C$ remains matched to $D$. The second corresponds to the case in which $B$ and $C$ form a new match while $A$ and $D$ become unmatched (or become matched to each other but in state 0). ${ }^{47}$ Let $\mathcal{A}_{j}$ denote the set of all possible allocations in a meeting that concerns $j$ agents. Then, $\mathcal{A}_{2}=\{\langle(A, B)\rangle,\langle(A),(B)\rangle\}$, $\mathcal{A}_{3}=\{\langle(A, B),(C)\rangle,\langle(A),(B, C)\rangle\}$ and $\mathcal{A}_{4}=\{\langle(A, B),(C, D)\rangle,\langle(B, C),(A, D)\rangle\}$. An allocation $a \in \mathcal{A}_{j}$ together with a payoff profile $\Pi \in \mathbb{R}^{j}$ constitute an outcome $[a, \Pi]$. For example, $\left[\langle(A),(B)\rangle,\left(\Pi_{A}, \Pi_{B}\right)\right]$ with $\Pi_{A}=\Pi_{B}=V_{0}$ is the outcome corresponding to a situation in which two unmatched agents meet and no match is formed. For any given meeting, a nonempty subset $S \subseteq I$ is called a coalition. Let $v$ denote a function that assigns a real number to each coalition $S$. The number $v(S)$ is called the worth of coalition $S$. Since utility is fully transferable, $v(S)$ summarizes the utility possibility set of coalition $S$. Intuitively, $v(S)$ is the total utility available to the coalition, which can then be distributed among the coalition members in any way. An outcome $[a, \Pi]$ is blocked by a coalition $S$ if there exists a payoff profile $\tilde{\Pi}$ with $\sum_{i \in S} \tilde{\Pi}_{i} \leq v(S)$ such that $\tilde{\Pi}_{i}>\Pi_{i}$ for all $i \in S$. With transferable utility, an outcome $[a, \Pi]$ is blocked by $S$ iff $\sum_{i \in S} \Pi_{i}<v(S)$. An outcome $[a, \Pi]$ that is feasible for the grand coalition (i.e., such that $\left.\sum_{i \in I} \Pi_{i} \leq v(I)\right)$ is in the core if there is no coalition $S$ that blocks this outcome. With transferable utility, an outcome $[a, \Pi]$ is in the core iff $\sum_{i \in S} \Pi_{i} \geq v(S)$ for

\footnotetext{
${ }^{47}$ We ignore other feasible allocations such as $\langle(A, C),(B, D)\rangle$, which would correspond to "break up both matches without forming a new one" because they will play no role in the analysis that follows.
} 
all $S \subseteq I$ and $\sum_{i \in I} \Pi_{i} \leq v(I) .{ }^{48}$

Proof of part (c) of Proposition 1. The proof proceeds in three steps.

(Step 1). First consider the case illustrated in Figure 1, where an unemployed worker $A$ and an unmatched employer $B$ meet and have the opportunity to form a match of productivity $y_{k}>$ 0 . For this case we have $I=\{A, B\}$, and the list of all possible coalitions is $\{A, B\},\{A\},\{B\}$. The worth of the grand coalition is $v(I)=\max \left(2 V_{0}, 2 V_{k}\right)=2 V_{k}$, while $v(\{A\})=v(\{B\})=V_{0}$. A vector of payoffs $\left(\Pi_{A}, \Pi_{B}\right)$ lies in the core if and only if $(i) \Pi_{A}+\Pi_{B}=2 V_{k}$; and $(i i) \Pi_{j} \geq V_{0}$ for $j=A, B$. We refer to the subgame that starts with $A$ making a take-it-or-leave-it offer to $B$ as "subgame 1." Figure 8 shows the core: it is the segment on the $\Pi_{A}+\Pi_{B}=2 V_{k}$ line that lies between the equilibrium payoffs of subgames 1 and 2 of the bilateral bargaining procedure. Both equilibrium payoffs as well as the expected payoff lie in the core.

(Step 2). Next consider the case illustrated in Figure 2: agent $B$, who is currently in a match of productivity $y_{i}$ with agent $A$, meets unmatched agent $C$ and they draw a productive opportunity $y_{k}$. Here $I=\{A, B, C\}$ and the list of all possible coalitions is $\{A, B, C\},\{A, B\}$, $\{A, C\},\{B, C\},\{A\},\{B\},\{C\}$. The corresponding values are $v(I)=\max \left(2 V_{i}+V_{0}, 2 V_{k}+V_{0}\right)$, $v(\{A, B\})=2 V_{i}, v(\{A, C\})=2 V_{0}, v(\{B, C\})=2 V_{k}, v(\{A\})=v(\{B\})=v(\{C\})=V_{0}$. Hence, a payoff profile $\Pi=\left(\Pi_{A}, \Pi_{B}, \Pi_{C}\right)$ belongs to the core if and only if: (i) $\Pi_{A}+\Pi_{B}+\Pi_{C}=$ $\max \left(2 V_{i}+V_{0}, 2 V_{k}+V_{0}\right)$; (ii) $\Pi_{A}+\Pi_{B} \geq 2 V_{i}$; (iii) $\Pi_{B}+\Pi_{C} \geq 2 V_{k}$; and (iv) $\Pi_{j} \geq V_{0}$ for $j=A, B, C$. If $V_{k}>V_{i}$, the four conditions can be rewritten as: (1) $\Pi_{A}=V_{0}$; (2) $\Pi_{B} \geq 2 V_{i}-V_{0}$; (3) $\Pi_{B}+\Pi_{C}=2 V_{k}$; and (4) $\Pi_{C} \geq V_{0}$. The first panel of Figure 9 illustrates the core for this case; it consists of all the payoffs $\left(V_{0}, \Pi_{B}, \Pi_{C}\right)$ such that $\left(\Pi_{B}, \Pi_{C}\right)$ lie on the segment of the $\Pi_{B}+\Pi_{C}=2 V_{k}$ line between the equilibrium payoffs of subgames 1 and 2 of the bilateral bargaining procedure (subgame 1 is the one that obtains when $B$ makes a take-it-or-leave-it offer to $C$, while subgame 2 is the one where $C$ makes the offer to $B$ ). From the figure it is clear

\footnotetext{
${ }^{48}$ Notice that in our random matching environment, the core is defined with respect to $I$, the set of agents who are involved in a meeting. (Since there is no central meeting place, the notion of a grand coalition of all the agents in the economy is meaningless here.)
} 
that the equilibrium payoffs of both subgames and the expected payoff all belong to the core. Conversely, if $V_{k}<V_{i}$, then the four conditions reduce to: (1') $\Pi_{A} \geq V_{0}$; (2') $\Pi_{B} \geq 2 V_{k}-V_{0}$; (3') $\Pi_{A}+\Pi_{B}=2 V_{i}$; and (4') $\Pi_{C}=V_{0}$. The second panel of Figure 9 illustrates the core for this case; it consists of all the payoffs $\left(\Pi_{A}, \Pi_{B}, V_{0}\right)$ such that $\left(\Pi_{A}, \Pi_{B}\right)$ lie on the segment of the $\Pi_{A}+\Pi_{B}=2 V_{i}$ line between the equilibrium payoffs of subgames 1 and 2 of the bilateral bargaining procedure (here subgame 1 is the one that obtains when $B$ makes a take-it-or-leaveit offer to $A$, while subgame 2 is the one where $A$ makes the offer to $B$ ). From the figure it is again clear that the equilibrium payoffs of both subgames and the expected payoff all belong to the core.

(Step 3). Finally, consider the case illustrated in Figure 3: while $A$ and $B$ are in a match of productivity $y_{i}$ and $C$ and $D$ are in a match of productivity $y_{j}$, agents $B$ and $C$ meet and draw a productive opportunity $y_{k}$. Here $I=\{A, B, C, D\}$ and the list of all possible coalitions is: $\{A, B, C, D\},\{A, B, C\},\{A, B, D\},\{B, C, D\},\{A, C, D\},\{A, B\},\{C, D\}$, $\{A, C\},\{B, D\},\{B, C\},\{A, D\},\{A\},\{B\},\{C\},\{D\}$. The corresponding values are $v(I)=$ $\max \left(2 V_{k}+2 V_{0}, 2 V_{i}+2 V_{j}\right), v(\{A, B, C\})=\max \left(2 V_{i}+V_{0}, 2 V_{k}+V_{0}\right), v(\{A, B, D\})=2 V_{i}+$ $V_{0}, v(\{B, C, D\})=\max \left(2 V_{j}+V_{0}, 2 V_{k}+V_{0}\right), v(\{A, C, D\})=2 V_{j}+V_{0}, v(\{A, B\})=2 V_{i}$, $v(\{C, D\})=2 V_{j}, v(\{A, C\})=v\{\{B, D\}\}=v\{\{A, D\}\}=2 V_{0}, v(\{A\})=v(\{B\})=$ $v(\{C\})=v(\{D\})=V_{0}$. A payoff profile $\Pi=\left(\Pi_{A}, \Pi_{B}, \Pi_{C}, \Pi_{D}\right)$ is in the core if and only if it satisfies the following inequalities: $\Pi_{A}+\Pi_{B}+\Pi_{C}+\Pi_{D}=\max \left(2 V_{k}+2 V_{0}, 2 V_{i}+2 V_{j}\right)$, $\Pi_{A}+\Pi_{B}+\Pi_{C} \geq \max \left(2 V_{i}+V_{0}, 2 V_{k}+V_{0}\right), \Pi_{B}+\Pi_{C}+\Pi_{D} \geq \max \left(2 V_{j}+V_{0}, 2 V_{k}+V_{0}\right), \Pi_{A}+$ $\Pi_{B}+\Pi_{D} \geq 2 V_{i}+V_{0}, \Pi_{A}+\Pi_{C}+\Pi_{D} \geq 2 V_{j}+V_{0}, \Pi_{A}+\Pi_{B} \geq 2 V_{i}, \Pi_{C}+\Pi_{D} \geq 2 V_{j}, \Pi_{B}+\Pi_{C} \geq 2 V_{k}$, $\Pi_{A}+\Pi_{C} \geq 2 V_{0}, \Pi_{B}+\Pi_{D} \geq 2 V_{0}, \Pi_{A}+\Pi_{D} \geq 2 V_{0}, \Pi_{j} \geq V_{0}$ for $j=A, B, C, D$. It is straightforward to verify that the equilibrium and expected payoffs of the bilateral bargaining procedure satisfy these fifteen inequalities.

Proof of Proposition 3. First consider the case of a continuing match when neither partner has an outside production opportunity. Every instant, with probability a half, the draw by 
Nature gives the bargaining power to the worker, who offers the employer $J_{0}$ (and keeps $M_{i}-J_{0}$ ). With the same probability Nature gives the bargaining power to the employer, who offers the worker $V_{0}+S_{i}$ (and keeps $M_{i}-V_{0}-S_{i}$ ). As a result, utility is continuously divided among the partners in such a way so that the worker's expected continuation payoff is $V_{i}=$ $V_{0}+\frac{1}{2}\left(M_{i}-M_{0}+S_{i}\right)$, and the employer's is $J_{i}=J_{0}+\frac{1}{2}\left(M_{i}-M_{0}-S_{i}\right)$. Next, we consider each of the bargaining situations listed in the statement of the proposition.

(a). An unmatched employer and an unemployed worker draw a new opportunity $y_{k}$.

With probability a half the worker has bargaining power, offers $J_{0}$, and the employer accepts. With the same probability the employer offers the worker $V_{0}$, and the worker accepts. The new match is formed regardless of who makes the offer and the expected payoffs are $V_{0}+\frac{1}{2}\left(M_{k}-M_{0}\right)$ for the worker and $J_{0}+\frac{1}{2}\left(M_{k}-M_{0}\right)$ for the employer. The individual expected capital gains to the worker and the employer each equal $\frac{1}{2}\left(M_{k}-M_{0}\right)$.

(b). An unmatched employer and an employed worker draw a new opportunity.

Suppose that worker $B$, who is currently employed in a match of quality $i$ with employer $A$, draws a new productive opportunity $y_{k}$ with an unmatched employer, $C$. We consider three cases.

Case 1: $M_{i}<M_{k}$. With probability a half the worker, $B$, has bargaining power. In this case he chooses to offer the new employer, $C, X_{B C}^{k}=J_{0}$, and she accepts. Thus, $B$ is able to appropriate $M_{k}-J_{0}$, the whole surplus from the new match. With probability another half, the employers $A$ and $C$ have bargaining power. In this case $B$ again chooses to bargain with $C$ first, who offers him $X_{C B}^{k}=M_{i}-J_{0}$, which is the maximum payoff $A$ is willing to offer $B$, so $B$ accepts $C$ 's offer. Regardless of whether the worker or the employers have bargaining power, the payoffs to $B$ and $C$ from forming a new match are larger than or equal to what they would obtain if $A$ and $B$ were to stay matched, and therefore the equilibrium outcome is that $B$ and $C$ form the new match. The expected payoffs are $\Pi_{A}=J_{0}, \Pi_{B}=\frac{1}{2}\left(M_{k}+M_{i}\right)-J_{0}$, and $\Pi_{C}=J_{0}+\frac{1}{2}\left(M_{k}-M_{i}\right)$. The expected capital gains are $\Gamma_{A}=-\frac{1}{2}\left(M_{i}-M_{0}-S_{i}\right), \Gamma_{B}=$ $\frac{1}{2}\left(M_{k}-M_{0}-S_{i}\right)$, and $\Gamma_{C}=\frac{1}{2}\left(M_{k}-M_{i}\right)$. 
Case 2: $M_{0}+S_{i}<M_{k}<M_{i}$. With probability a half the worker, $B$, has bargaining power. In this case $B$ offers his old employer, $A, X_{B A}^{i}=J_{0}$, and she accepts. With the same probability, the employers, $A$ and $C$, have bargaining power. In this case, $B$ also chooses to bargain with $A$ first, who makes $B$ an offer $X_{A B}^{i}=M_{k}-J_{0}$, the maximum $C$ can offer, and $B$ accepts to stay matched with $A$. Regardless of whether the worker or the employers have bargaining power, the equilibrium outcome will be that $B$ chooses to stay matched with $A$. The equilibrium expected payoffs are $\Pi_{A}=J_{0}+\frac{1}{2}\left(M_{i}-M_{k}\right), \Pi_{B}=\frac{1}{2}\left(M_{i}+M_{k}\right)-J_{0}$, and $\Pi_{C}=J_{0}$. The expected gains are $\Gamma_{B}=-\Gamma_{A}=\frac{1}{2}\left(M_{k}-M_{0}-S_{i}\right)$ and $\Gamma_{C}=0$.

Case 3: $M_{k}<M_{0}+S_{i}$. With probability a half the worker, $B$, has bargaining power, he offers $A X_{B A}^{i}=J_{0}$, and they stay matched. With probability a half, the employers $(A$ and $C)$ have bargaining power, and $B$ chooses to bargain with $A$ first. The fact that $M_{k}<M_{0}+S_{i}$ means that $A$ only needs to offer $B$ payoff $X_{A B}^{i}=V_{0}+S_{i}$ to convince him to stay in the match. Thus, regardless of whether the worker or the employers have bargaining power, $B$ stays matched to $A$. The equilibrium expected payoffs are $\Pi_{A}=J_{i}, \Pi_{B}=V_{i}$, and $\Pi_{C}=J_{0}$, and the expected gains are $\Gamma_{A}=\Gamma_{B}=\Gamma_{C}=0$.

(c). A matched employer and an unemployed worker draw a new opportunity.

Suppose that employer $B$, who is currently in a match of quality $i$ with worker $A$, draws a new production opportunity $y_{k}$ with an unemployed worker $C$. In order for $B$ and $C$ to form the new match, they have to pay $T_{i}$ to the government. Thus the total value of the new match to the agents in the bargaining $(A, B$, and $C)$ is $M_{k}^{\prime} \equiv M_{k}-T_{i}$ instead of $M_{k}$. By the same reasoning used in (b) above, and replacing $M_{k}$ with $M_{k}^{\prime}$, we obtain the following expected gains from trade:

Case 1: $M_{i}<M_{k}^{\prime} . \Gamma_{A}=-\frac{1}{2}\left(M_{i}-M_{0}-S_{i}\right), \Gamma_{B}=\frac{1}{2}\left(M_{k}^{\prime}-M_{0}-S_{i}\right)$ and $\Gamma_{C}=\frac{1}{2}\left(M_{k}^{\prime}-M_{i}\right)$.

Case 2: $M_{0}+S_{i}<M_{k}^{\prime}<M_{i}$. $\Gamma_{B}=-\Gamma_{A}=\frac{1}{2}\left(M_{k}^{\prime}-M_{0}-S_{i}\right)$ and $\Gamma_{C}=0$.

Case 3: $M_{k}^{\prime}<M_{0}+S_{i} . \Gamma_{A}=\Gamma_{B}=\Gamma_{C}=0$.

(d). A matched employer and an employed worker draw a new opportunity.

Suppose that employer $B$ and worker $C$ meet and draw a productive opportunity $y_{k}$. The 
situation now is that $B$ is currently in a match of productivity $y_{i}$ with worker $A$, while $C$ is currently in a match of productivity $y_{j}$ with employer $D$. We divide the analysis into four cases and assume, without loss of generality, that $M_{i}+S_{j} \leq M_{j}+S_{i}$.

Case 1: $M_{i}+M_{j}-M_{0}<M_{k}-T_{i} \equiv M_{k}^{\prime}$. Because the sum of the values of the new match (net of taxes) and the unmatched exceeds the sum of the values of the existing matches, the agent who does not have bargaining power chooses to bargain with the new partner first. With probability a half the employers $(B$ and $D)$ have bargaining power. In this case, $B$ and $C$ negotiate first, and $B$ offers him $X_{B C}^{k}$. To determine her offer, $B$ must take into account that $C$ can then go on to bargain with $D$ holding $X_{B C}^{k}$ as his outside option. Employer $D$ will be able to outbid $B$ 's offer as long as $M_{j}-X_{B C}^{k}>J_{0}$. Thus, $B$ can ensure that $C$ will want to match with her by offering $X_{B C}^{k}=M_{j}-J_{0}$. A similar reasoning implies that with probability another half, when the workers $A$ and $C$ have bargaining power, $B$ and $C$ bargain first, and $C$ will offer $X_{C B}^{k}=M_{i}-V_{0}-S_{i}$ to $B$. In both situations, when the employers have bargaining power and when the workers have bargaining power, $B$ and $C$ are better off by leaving their partners and matching with each other. The expected payoffs are $\Pi_{A}=V_{0}+S_{i}, \Pi_{B}=J_{i}+\frac{1}{2}\left(M_{k}^{\prime}-M_{j}-S_{i}\right)$, $\Pi_{C}=V_{j}+\frac{1}{2}\left(M_{k}^{\prime}-M_{i}-S_{j}\right)$, and $\Pi_{D}=J_{0}$. The expected gains are $\Gamma_{A}=-\frac{1}{2}\left(M_{i}-M_{0}-S_{i}\right)$, $\Gamma_{B}=\frac{1}{2}\left(M_{k}^{\prime}-M_{j}-S_{i}\right), \Gamma_{C}=\frac{1}{2}\left(M_{k}^{\prime}-M_{i}-S_{j}\right)$, and $\Gamma_{D}=-\frac{1}{2}\left(M_{j}-M_{0}-S_{j}\right)$.

Case 2: $M_{j}+S_{i}<M_{k}^{\prime}<M_{i}+M_{j}-M_{0}$. Since the sum of the values of the existing matches exceeds the sum of the values of the new match (net of taxes) and the unmatched, the agent without bargaining power chooses to bargain with the old partner first. With probability a half, the workers $(A$ and $C$ ) have bargaining power. Then $B$ chooses to first bargain with $A$. When choosing his offer $X_{A B}^{i}$, worker $A$ takes into account the fact that $B$ can continue to bargain with the new worker, $C$, holding $X_{A B}^{i}$ as her outside option. $A$ knows that $C$ will outbid $X_{A B}^{i}$ as long as $C$ 's payoff from forming the new match with $B$ by paying $X_{A B}^{i}$, namely $M_{k}^{\prime}-X_{A B}^{i}-S_{i}$ is higher than $C$ 's payoff from staying matched with $D$, namely $M_{j}-J_{0}$. So in order for $A$ to win $B$ over $C, A$ needs to offer $B$ a payoff $X_{A B}^{i}=M_{k}^{\prime}-M_{j}+J_{0}-S_{i}$. This leaves $A$ with payoff $M_{i}-\left(M_{k}^{\prime}-M_{j}+J_{0}-S_{i}\right)>V_{0}+S_{i}$, so $A$ and $B$ stay matched. 
Worker $C$ also stays matched to his old employer, $D$, and since he has bargaining power, $B$ captures the whole surplus of that match $\left(M_{j}-J_{0}\right)$ for himself. Similar arguments imply that when, with probability another half, employers $B$ and $D$ have bargaining power, $C$ chooses to bargain with $D$ first, $D$ offers $C X_{D C}^{j}=M_{k}^{\prime}-M_{i}+V_{0}$, and $C$ accepts to stay matched to $D$. Also, $B$ stays matched to $A$ and captures the whole surplus, $M_{i}-V_{0}-S_{i}$. In every case the equilibrium outcome is that $B$ and $C$ each decide to stay in the current match. The equilibrium expected payoffs are $\Pi_{A}=V_{i}-\frac{1}{2}\left(M_{k}^{\prime}-M_{j}-S_{i}\right), \Pi_{B}=J_{i}+\frac{1}{2}\left(M_{k}^{\prime}-M_{j}-S_{i}\right)$, $\Pi_{C}=V_{j}+\frac{1}{2}\left(M_{k}^{\prime}-M_{i}-S_{j}\right)$, and $\Pi_{D}=J_{j}-\frac{1}{2}\left(M_{k}^{\prime}-M_{i}-S_{j}\right)$. The corresponding capital gains are $\Gamma_{B}=-\Gamma_{A}=\frac{1}{2}\left(M_{k}^{\prime}-M_{j}-S_{i}\right)$, and $\Gamma_{C}=-\Gamma_{D}=\frac{1}{2}\left(M_{k}^{\prime}-M_{i}-S_{j}\right)$.

Case 3: $M_{i}+S_{j}<M_{k}^{\prime}<M_{j}+S_{i}$. As in the previous case, if the employers ( $B$ and $D$ ) have bargaining power, then $C$ chooses to bargain with $D$ first, and $D$ offers $X_{D C}^{j}=M_{k}^{\prime}-M_{i}+V_{0}$. (As in the previous case, this is the minimum offer that guarantees that $D$ will not be outbid by $B$.) In the event that the workers $(A$ and $C$ ) have bargaining power, $B$ chooses to bargain with $A$ first. But in this case, $A$ only needs to offer $B$ payoff $X_{A B}^{i}=J_{0}$ to convince her to stay in the match. (The reason is that if $B$ were to continue to bargain with $C$, the most that $C$ would be willing to offer $B$ in order to form a new match is $M_{k}^{\prime}-M_{j}+J_{0}-S_{i}<J_{0}$; therefore when making his offer, $A$ can effectively ignore the fact that $B$ has the option to continue to bargain with $C$.) Again, the equilibrium outcome is that $B$ and $C$ stay with their current partners, but this time $C$ is able to extract a side payment from $D$ while $B$ gets no side payment from $A$. The equilibrium expected payoffs are $\Pi_{A}=V_{i}, \Pi_{B}=J_{i}, \Pi_{C}=V_{j}+\frac{1}{2}\left(M_{k}^{\prime}-M_{i}-S_{j}\right)$, and $\Pi_{D}=J_{j}-\frac{1}{2}\left(M_{k}^{\prime}-M_{i}-S_{j}\right)$. The capital gains are $\Gamma_{A}=\Gamma_{B}=0$, and $\Gamma_{C}=-\Gamma_{D}=$ $\frac{1}{2}\left(M_{k}^{\prime}-M_{i}-S_{j}\right)$.

Case 4: $M_{k}^{\prime}<M_{i}+S_{j}$. Using a reasoning similar to the one we used above, in this case the productivity of the new match is so low relative to the current matches, that the option to form a new match allows neither $B$ nor $C$ to extract side-payments from their current partners. The outcome is that $B$ and $C$ stay matched to their old partners, the equilibrium expected payoffs are $\Pi_{A}=V_{i}, \Pi_{B}=J_{i}, \Pi_{C}=V_{j}$, and $\Pi_{D}=J_{j}$, and the expected gains are nil to all. 
Proof of Lemma 1. The values of an unemployed worker and an unmatched employer solve

$$
\begin{aligned}
& r V_{0}-\dot{V}_{0}=\alpha n_{0} \sum_{k=1}^{N} \pi_{k} \phi_{00}^{k} \frac{M_{k}-M_{0}}{2}+\alpha \sum_{j=1}^{N} \sum_{k=1}^{N} n_{j} \pi_{k} \phi_{0 j}^{k} \frac{M_{k}-M_{j}-T_{j}}{2} \\
& r J_{0}-\dot{J}_{0}=\alpha n_{0} \sum_{k=1}^{N} \pi_{k} \phi_{00}^{k} \frac{M_{k}-M_{0}}{2}+\alpha \sum_{j=1}^{N} \sum_{k=1}^{N} n_{j} \pi_{k} \phi_{j 0}^{k} \frac{M_{k}-M_{j}}{2} .
\end{aligned}
$$

Adding these expressions and using Proposition 3 leads to (14). A worker employed in a match of type $i$ earns wage $w_{i}$ and his expected payoff satisfies

$$
\begin{aligned}
r V_{i}-\dot{V}_{i}= & w_{i}-\delta\left(V_{i}-V_{0}\right) \\
& +\alpha n_{0} \sum_{k=1}^{N} \pi_{k}\left[\phi_{i 0}^{k} \frac{M_{k}-M_{0}-S_{i}}{2}+\left(1-\phi_{i 0}^{k}\right) \max \left(\frac{M_{k}-M_{0}-S_{i}}{2}, 0\right)\right] \\
& -\alpha n_{0} \sum_{k=1}^{N} \pi_{k}\left[\phi_{0 i}^{k} \frac{M_{i}-M_{0}-S_{i}}{2}+\left(1-\phi_{0 i}^{k}\right) \max \left(\frac{M_{k}-M_{0}-S_{i}-T_{i}}{2}, 0\right)\right] \\
& +\alpha \sum_{j=1}^{N} \sum_{k=1}^{N} n_{j} \pi_{k}\left[\phi_{i j}^{k} \frac{M_{k}-M_{j}-S_{i}-T_{j}}{2}+\left(1-\phi_{i j}^{k}\right) \max \left(\frac{M_{k}-M_{j}-S_{i}-T_{j}}{2}, 0\right)\right] \\
& -\alpha \sum_{j=1}^{N} \sum_{k=1}^{N} n_{j} \pi_{k}\left[\phi_{j i}^{k} \frac{M_{i}-M_{0}-S_{i}}{2}+\left(1-\phi_{j i}^{k}\right) \max \left(\frac{M_{k}-M_{j}-S_{i}-T_{i}}{2}, 0\right)\right] .
\end{aligned}
$$

Similarly, the value of an employer in a match of productivity $y_{i}$ is:

$$
\begin{aligned}
r J_{i}-\dot{J}_{i}= & 2 y_{i}-w_{i}-\delta\left(J_{i}-J_{0}\right) \\
& +\alpha n_{0} \sum_{k=1}^{N} \pi_{k}\left[\phi_{0 i}^{k} \frac{M_{k}-M_{0}-S_{i}-T_{i}}{2}+\left(1-\phi_{0 i}^{k}\right) \max \left(\frac{M_{k}-M_{0}-S_{i}-T_{i}}{2}, 0\right)\right] \\
& -\alpha n_{0} \sum_{k=1}^{N} \pi_{k}\left[\phi_{i 0}^{k} \frac{M_{i}-M_{0}-S_{i}}{2}+\left(1-\phi_{i 0}^{k}\right) \max \left(\frac{M_{k}-M_{0}-S_{i}}{2}, 0\right)\right] \\
& +\alpha \sum_{j=1}^{N} \sum_{k=1}^{N} n_{j} \pi_{k}\left[\phi_{j i}^{k} \frac{M_{k}-M_{j}-S_{i}-T_{i}}{2}+\left(1-\phi_{j i}^{k}\right) \max \left(\frac{M_{k}-M_{j}-S_{i}-T_{i}}{2}, 0\right)\right] \\
& -\alpha \sum_{j=1}^{N} \sum_{k=1}^{N} n_{j} \pi_{k}\left[\phi_{i j}^{k} \frac{M_{i}-M_{0}-S_{i}}{2}+\left(1-\phi_{i j}^{k}\right) \max \left(\frac{M_{k}-M_{j}-S_{i}-T_{j}}{2}, 0\right)\right] .
\end{aligned}
$$

Adding the last two expressions and using Proposition 3 lead to (13). 
Proof of Lemma 2. The values of an unemployed worker and an unmatched employer solve

$$
\begin{aligned}
& r V_{0}-\dot{V}_{0}=\alpha m_{0} \sum_{k=1}^{N} \pi_{k} \phi_{00}^{k} \frac{M_{k}-M_{0}}{2}+\alpha \sum_{j=1}^{N} \sum_{k=1}^{N} n_{j} \pi_{k} \phi_{0 j}^{k} \frac{M_{k}-M_{j}-T_{j}}{2} \\
& r J_{0}-\dot{J}_{0}=-c+\alpha n_{0} \sum_{k=1}^{N} \pi_{k} \phi_{00}^{k} \frac{M_{k}-M_{0}}{2}+\alpha \sum_{j=1}^{N} \sum_{k=1}^{N} n_{j} \pi_{k} \phi_{j 0}^{k} \frac{M_{k}-M_{j}}{2} .
\end{aligned}
$$

A worker employed in a match of type $i$ earns wage $w_{i}$ and his expected payoff satisfies

$$
\begin{aligned}
r V_{i}-\dot{V}_{i}= & w_{i}-\delta\left(V_{i}-V_{0}\right) \\
& +\alpha m_{0} \sum_{k=1}^{N} \pi_{k}\left[\phi_{i 0}^{k} \frac{M_{k}-M_{0}-S_{i}}{2}+\left(1-\phi_{i 0}^{k}\right) \max \left(\frac{M_{k}-M_{0}-S_{i}}{2}, 0\right)\right] \\
& -\alpha n_{0} \sum_{k=1}^{N} \pi_{k}\left[\phi_{0 i}^{k} \frac{M_{i}-M_{0}-S_{i}}{2}+\left(1-\phi_{0 i}^{k}\right) \max \left(\frac{M_{k}-M_{0}-S_{i}-T_{i}}{2}, 0\right)\right] \\
& +\alpha \sum_{j=1}^{N} \sum_{k=1}^{N} n_{j} \pi_{k}\left[\phi_{i j}^{k} \frac{M_{k}-M_{j}-S_{i}-T_{j}}{2}+\left(1-\phi_{i j}^{k}\right) \max \left(\frac{M_{k}-M_{j}-S_{i}-T_{j}}{2}, 0\right)\right] \\
& -\alpha \sum_{j=1}^{N} \sum_{k=1}^{N} n_{j} \pi_{k}\left[\phi_{j i}^{k} \frac{M_{i}-M_{0}-S_{i}}{2}+\left(1-\phi_{j i}^{k}\right) \max \left(\frac{M_{k}-M_{j}-S_{i}-T_{i}}{2}, 0\right)\right] .
\end{aligned}
$$

Similarly, the value of an employer in a match of productivity $y_{i}$ is:

$$
\begin{aligned}
r J_{i}-\dot{J}_{i}= & 2 y_{i}-w_{i}-\delta\left(J_{i}-J_{0}\right) \\
& +\alpha n_{0} \sum_{k=1}^{N} \pi_{k}\left[\phi_{0 i}^{k} \frac{M_{k}-M_{0}-S_{i}-T_{i}}{2}+\left(1-\phi_{0 i}^{k}\right) \max \left(\frac{M_{k}-M_{0}-S_{i}-T_{i}}{2}, 0\right)\right] \\
& -\alpha m_{0} \sum_{k=1}^{N} \pi_{k}\left[\phi_{i 0}^{k} \frac{M_{i}-M_{0}-S_{i}}{2}+\left(1-\phi_{i 0}^{k}\right) \max \left(\frac{M_{k}-M_{0}-S_{i}}{2}, 0\right)\right] \\
& +\alpha \sum_{j=1}^{N} \sum_{k=1}^{N} n_{j} \pi_{k}\left[\phi_{j i}^{k} \frac{M_{k}-M_{j}-S_{i}-T_{i}}{2}+\left(1-\phi_{j i}^{k}\right) \max \left(\frac{M_{k}-M_{j}-S_{i}-T_{i}}{2}, 0\right)\right] \\
& -\alpha \sum_{j=1}^{N} \sum_{k=1}^{N} n_{j} \pi_{k}\left[\phi_{i j}^{k} \frac{M_{i}-M_{0}-S_{i}}{2}+\left(1-\phi_{i j}^{k}\right) \max \left(\frac{M_{k}-M_{j}-S_{i}-T_{j}}{2}, 0\right)\right] .
\end{aligned}
$$

The expressions in the statement of the lemma result from using Proposition 3, and adding (36) to (37), and (34) to (35). 


\section{Free entry with constant returns meeting technology.}

Suppose the aggregate meeting technology is given by a function $\xi(m, n)$, which is monotonic in both arguments and homogeneous of degree one. Since $n=1$, in this alternative formulation an employer contacts a random worker at rate $\alpha(m) \equiv \xi(1,1 / m)$ and a worker contacts a random employer at rate $m \alpha(m)$. So the probability an employer meets a worker who is employed in a match of type $i$ is $\alpha(m) n_{i}$, and the probability a worker meets an employer who is in a match of type $i$ is $\alpha(m) m_{j}$. Therefore, if we replace $\alpha$ with $\alpha(m)$, the Hamiltonian,

the flow equations (15) and (16), and the optimality conditions for $\tau_{i j}^{k}$ are all unchanged, while since $m=1-n_{0}+m_{0}$, condition (17) becomes

$$
\begin{aligned}
C^{\prime}\left(m_{0}\right)= & \alpha(m) \sum_{i=0}^{N} \sum_{k=1}^{N} n_{i} \pi_{k} \tau_{i 0}^{k}\left(\lambda_{k}-\lambda_{i}\right)+\alpha^{\prime}(m) m_{0} \sum_{i=0}^{N} \sum_{k=1}^{N} n_{i} \pi_{k} \tau_{i 0}^{k}\left(\lambda_{k}-\lambda_{i}\right) \\
& +\alpha^{\prime}(m) \sum_{i=0}^{N} \sum_{j=1}^{N} \sum_{k=1}^{N} n_{i} n_{j} \pi_{k} \tau_{i j}^{k}\left(\lambda_{k}+\lambda_{0}-\lambda_{i}-\lambda_{j}\right) .
\end{aligned}
$$

The Euler equations associated with $n_{i}$ for $i=1, \ldots, n$ are as in Section 5 (again, after replacing $\alpha$ with $\alpha(m))$, but since $\alpha(m)=\alpha\left(1-n_{0}+m_{0}\right)$, the one associated with $n_{0}$ is now

$$
\begin{aligned}
r \lambda_{0}-\dot{\lambda}_{0}= & \alpha(m) m_{0} \sum_{k=1}^{N} \pi_{k} \tau_{00}^{k}\left(\lambda_{k}-\lambda_{0}\right)+\alpha(m) \sum_{j=1}^{N} \sum_{k=1}^{N} n_{j} \pi_{k} \tau_{0 j}^{k}\left(\lambda_{k}-\lambda_{j}\right) \\
& -\alpha^{\prime}(m) m_{0} \sum_{i=0}^{N} \sum_{k=1}^{N} n_{i} \pi_{k} \tau_{i 0}^{k}\left(\lambda_{k}-\lambda_{i}\right) \\
& -\alpha^{\prime}(m) \sum_{i=0}^{N} \sum_{j=1}^{N} \sum_{k=1}^{N} n_{i} n_{j} \pi_{k} \tau_{i j}^{k}\left(\lambda_{k}+\lambda_{0}-\lambda_{i}-\lambda_{j}\right) .
\end{aligned}
$$

Using (38), which holds as long as $m_{0}>0$, and collecting terms, this last condition becomes

$$
\begin{aligned}
r \lambda_{0}-\dot{\lambda}_{0}= & -C^{\prime}\left(m_{0}\right)+\alpha(m)\left(m_{0}+n_{0}\right) \sum_{k=1}^{N} \pi_{k} \tau_{00}^{k}\left(\lambda_{k}-\lambda_{0}\right) \\
& +\alpha(m) \sum_{j=1}^{N} \sum_{k=1}^{N} n_{j} \pi_{k}\left(\tau_{0 j}^{k}+\tau_{j 0}^{k}\right)\left(\lambda_{k}-\lambda_{j}\right) .
\end{aligned}
$$

Summarizing, the optimality conditions for the economy with a constant returns meeting technology are (3) and (38), together with (18) and (19), but with $\alpha=\alpha(m)$. Comparing these 
optimal conditions with the conditions for the competitive matching equilibrium: (15), (16), (20), (21), and (22) — which remain unchanged - we learn that the constant-returns-to-scale aggregate matching function fails to solve the inefficiency associated with the search externality. (See footnote 14.)

Lemma 3 A unique steady state distribution of workers exists for any given $\phi \in[0,1]$. The number of unemployed workers, $n_{0}$, solves

$$
\left[\alpha n_{0}^{2}-\delta\left(1-n_{0}\right)\right]\left(\delta+2 \alpha \pi n_{0}\right)^{2}-\phi \alpha \pi\left[2 \delta\left(1-n_{0}\right)-\alpha(1+\pi) n_{0}^{2}\right]^{2}=0
$$

The number of workers employed in matches with productivity $y_{1}$ is $n_{1}=\frac{2 \delta\left(1-n_{0}\right)-\alpha(1+\pi) n_{0}^{2}}{\delta+2 \alpha \pi n_{0}}$, and the number of workers employed in matches with productivity $y_{2}$ is $n_{2}=1-n_{0}-n_{1}$.

Proof of Lemma 3. Combining the $\dot{n}_{2}=0$ and $\dot{n}_{0}=0$ conditions, we find that $n_{1}=f\left(n_{0}\right)$, where $f\left(n_{0}\right) \equiv \frac{2 \delta\left(1-n_{0}\right)-\alpha(1+\pi) n_{0}^{2}}{\delta+2 \alpha \pi n_{0}}$. It can be shown that $f^{\prime}\left(n_{0}\right)<0$ on $[0,1]$, so to each $n_{0} \in[0,1]$ corresponds a unique $n_{1}$. In addition, $f\left(n_{0}\right) \geq 0$ if $n_{0} \leq \bar{\eta}_{0}$ and $f\left(n_{0}\right) \leq 1$ if $n_{0} \geq \underline{\eta_{0}}$, where $\bar{\eta}_{0}=\frac{\sqrt{\delta^{2}+2 \alpha \delta(1+\pi)}-\delta}{\alpha(1+\pi)}$ and $\underline{\eta_{0}}=\frac{\sqrt{(\delta+\alpha \pi)^{2}+\alpha \delta(1+\pi)}-(\delta+\alpha \pi)}{\alpha(1+\pi)}$, with $0<\underline{\eta_{0}}<\bar{\eta}_{0}<1$. Substituting $n_{1}=f\left(n_{0}\right)$ back into the $\dot{n}_{0}=0$ condition delivers a single equation in $n_{0}$ which can be written as $G\left(n_{0} ; \phi\right)=0$, where

$$
G\left(n_{0} ; \phi\right) \equiv\left[\alpha n_{0}^{2}-\delta\left(1-n_{0}\right)\right]\left(\delta+2 \alpha \pi n_{0}\right)^{2}-\alpha \pi \phi\left[2 \delta\left(1-n_{0}\right)-\alpha(1+\pi) n_{0}^{2}\right]^{2}
$$

Direct calculations reveal that $G\left(\bar{\eta}_{0} ; \phi\right)=\alpha \bar{\eta}_{0}^{2}-\delta\left(1-\bar{\eta}_{0}\right)>0$ for all $\phi \in[0,1]$, and also that $G\left(\underline{\eta_{0}} ; \phi, \psi\right)$ has the same sign as $\alpha{\underline{\eta_{0}}}^{2}-\delta\left(1-\underline{\eta_{0}}\right)-\alpha \pi \phi$. Note that an increase in $\phi$ causes $G$ to shift down uniformly, so to ensure $G\left(\underline{\eta_{0}} ; \phi\right)<0$ for all $\phi$, it suffices to guarantee that $G\left(\underline{\eta_{0}} ; 0\right)<0$. This condition can be written as $\alpha{\underline{\eta_{0}}}^{2}-\delta\left(1-\underline{\eta_{0}}\right)<0$, a parametric restriction that is always satisfied. So a steady state exists. Finally, note that $\left.\frac{\partial G\left(n_{0} ; \phi\right)}{\partial n_{0}}\right|_{G\left(n_{0} ; \phi\right)=0}>0$, which together with the fact that $f^{\prime}\left(n_{0}\right)<0$ implies that the steady state is unique. 
Lemma 4 The transition function for the stochastic process that rules a worker's state is

$$
\left[p_{i j}^{(t)}\right]=\sum_{n=0}^{\infty} \frac{(a t)^{n} e^{-a t}}{n !} K^{n},
$$

where $a \equiv 2 \alpha+\delta$, and

$$
K=\left[\begin{array}{ccc}
\frac{\delta+\alpha\left(2-m_{0}-\pi \psi n_{1}\right)}{2 \alpha+\delta} & \frac{\alpha(1-\pi) m_{0}}{2 \alpha+\delta} & \frac{\alpha \pi\left(m_{0}+\psi n_{1}\right)}{2 \alpha+\delta} \\
\frac{\delta+\alpha \pi\left(\psi n_{0}+\phi n_{1}\right)}{2 \alpha+\delta} & \frac{\alpha\left[2-\pi\left(m_{0}+\psi n_{0}+2 \phi n_{1}\right)\right]}{2 \alpha+\delta} & \frac{\alpha \pi\left(m_{0}+\phi n_{1}\right)}{2 \alpha+\delta} \\
\frac{\delta}{2 \alpha+\delta} & 0 & \frac{2 \alpha}{2 \alpha+\delta}
\end{array}\right]
$$

Proof of Lemma 4. Each match is subject to three independent Poisson processes: one with arrival rate $\delta$ (the exogenous destruction process), and two with arrival rate $\alpha$ (the process according to which the employer meets other workers and the one according to which the worker meets other employers). Conditional on the arrival of one of these Poisson events, the worker transits from state $i$ to state $j$ according to $K=\frac{\delta}{a} K_{\delta}+\frac{\alpha}{a} K_{\alpha}^{e}+\frac{\alpha}{a} K_{\alpha}^{w}$, where

$$
\begin{aligned}
K_{\delta}= & {\left[\begin{array}{lll}
1 & 0 & 0 \\
1 & 0 & 0 \\
1 & 0 & 0
\end{array}\right] } \\
K_{\alpha}^{e}= & {\left[\begin{array}{ccc}
1 & & 0 \\
\pi\left(\psi n_{0}+\phi n_{1}\right) & 1-\pi\left(\psi n_{0}+\phi n_{1}\right) & 0 \\
0 & 0 & 1
\end{array}\right] } \\
K_{\alpha}^{w}= & {\left[\begin{array}{ccc}
1-m_{0}-\pi \psi n_{1} & (1-\pi) m_{0} & \pi\left(m_{0}+\psi n_{1}\right) \\
0 & 1-\pi\left(m_{0}+\phi n_{1}\right) & \pi\left(m_{0}+\phi n_{1}\right) \\
0 & 0 & 1
\end{array}\right] . }
\end{aligned}
$$

Then, given the number of arrivals over a period of length $t$ follows a Poisson distribution with parameter at, (40) follows. See Cox and Miller (1965) for more details. 


\section{References}

[1] Albæk, Karsten, and Bent E. Sørensen. "Worker Flows and Job Flows in Danish Manufacturing, 1980-91." Economic Journal 105(451) (November 1998): 1750-1771.

[2] Anderson, Patricia, and Bruce D. Meyer. "The Extent and Consequences of Job Turnover." Brookings Papers on Economic Activity. Microeconomics, 1994: 177-248.

[3] Bertola, Giuseppe, and Richard Rogerson. "Institutions and Labor Reallocation." European Economic Review 41 (1997): 1147-1171.

[4] Blanchard, Olivier, and Pedro Portugal. "What Hides Behind an Unemployment Rate: Comparing Portuguese and U.S. Labor Markets." American Economic Review 91(1) (March 2001): 187-207.

[5] Blau, David M., and Philip K. Robins. "Job Search Outcomes for the Employed and Unemployed." Journal of Political Economy 98(3) (1990): 637-654.

[6] Bontemps, Christian, Jean-Marc Robin, and Gerard J. van den Berg. "An Empirical Equilibrium Job Search Model with Search On-the-Job and Heterogeneous Workers and Firms." International Economic Review 40(4) (November 1999): 1039-1074.

[7] Bontemps, Christian, Jean-Marc Robin, and Gerard J. van den Berg. "Equilibrium Search with Continuous Productivity Dispersion: Theory and Nonparametric Estimation." International Economic Review 41(2) (May 2000): 305-358.

[8] Burdett, Kenneth. "A Theory of Employee Job Search and Quit Rates." American Economic Review 68(1) (March 1978): 212-220.

[9] Burdett, Kenneth, and Melvyn Coles. "Marriage and Class." Quarterly Journal of Economics 112(1) (February 1997): 141-168. 
[10] Burdett, Kenneth, and Melvyn Coles. "Equilibrium Wage Tenure Contracts." Econometrica 71(5) (September 2003): 1377-1404.

[11] Burdett, Kenneth, Ryoichi Imai, and Randall Wright. "Unstable Relationships." Frontiers of Macroeconomics: Vol. 1: No. 1, Article 1, 2004.

[12] Burdett, Kenneth, Ricardo Lagos, and Randall Wright. "An On-the-Job Search Model of Unemployment, Inequality, and Crime." International Economic Review 45(3) (August 2004): 681-706.

[13] Burdett, Kenneth, and Dale T. Mortensen. "Wage Differentials, Employer Size and Unemployment." International Economic Review 39 (1998): 257-273.

[14] Burgess, Simon, Julia Lane, and David Stevens. "Job Flows, Worker Flows, and Churning." Journal of Labor Economics 18(3) (July 2000): 473-502.

[15] Coles, Melvyn. "Equilibrium Wage Dispersion, Firm Size, and Growth." Review of Economic Dynamics 4(1) (January 2001): 159-187.

[16] Cornelius, Tracy. "A Search Model of Marriage and Divorce." Review of Economic Dynamics 6(1) (January 2003): 135-155.

[17] Cox, D. R., and H. D. Miller. The Theory of Stochastic Processes. London: Chapman and Hall, 1965.

[18] Davis, Steven J., and John Haltiwanger. "Gross Job Creation, Gross Job Destruction, and Employment Reallocation." Quarterly Journal of Economics 107(3) (August 1992): 819-863.

[19] Davis, Steven J., and John Haltiwanger. "Measuring Gross Worker and Job Flows." In Labor Statistics Measurement Issues, edited by John Haltiwanger, Marilyn Manser and Robert Topel. Chicago: University of Chicago Press, 1999, 77-122. 
[20] Davis, Steven J., John Haltiwanger and Scott Schuh. Job Creation and Destruction. Cambridge, MA: MIT Press, 1996.

[21] Dey, Matthew S., and Christopher J. Flinn. "An Equilibrium Model of Health Insurance Provision and Wage Determination." Econometrica 73(2) (March 2005): 571-627.

[22] Diamond, Peter A. "Wage Determination and Efficiency in Search Equilibrium," Review of Economic Studies 49(2) (April 1982a): 217-227.

[23] Diamond, Peter A. "Aggregate Demand Management in Search Equilibrium." Journal of Political Economy 90(5) (October 1982b): 881-894.

[24] Diamond, Peter A., and Eric S. Maskin. "An Equilibrium Analysis of Search and Breach of Contract I: Steady States." Bell Journal of Economics 10(1) (September 1979): 282-316.

[25] Diamond, Peter A., and Eric S. Maskin. "Externalities and Efficiency in a Model of Stochastic Job Matching." MIT mimeo, November 1981.

[26] Fallick, Bruce C., and Charles A. Fleischman. "The Importance of Employer-to-Employer Flows in the U.S. Labor Market," Finance and Economics Discussion Series 2001-18, Board of Governors of the Federal Reserve System, 2001.

[27] Felli, Leonardo, and Kevin Roberts. "Does Competition Solve the Hold-up Problem?" STICERD Theoretical Economics Discussion Paper TE/01/414, London School of Economics, 2001.

[28] Hamermesh, Daniel S., Wolter H. J. Hassink and Jan C. van Ours. "Job Turnover and Labor Turnover: A Taxonomy of Employment Dynamics." Annales D'Économie et de Statistique 41/42 (1996): 21-40.

[29] Jacobson, Louis S., Robert J. LaLonde, and Daniel G. Sullivan. "Earnings Losses of Displaced Workers." American Economic Review 83(4) (September 1993): 685-709. 
[30] Jovanovic, Boyan. "Job Matching and the Theory of Turnover." Journal of Political Economy 87(5) pt. 1 (October 1979): 972-990.

[31] Lazear, Edward, P. "Job Security Provisions and Employment." Quarterly Journal of Economics 105(3) (August 1990): 699-726.

[32] Lippman, Steven A., and John, J. McCall. "The Economics of Search: A Survey. Part I." Economic Inquiry 14 (June 1976): 155-189.

[33] Ljungqvist, Lars, and Thomas J. Sargent. "The European Unemployment Dilemma," Journal of Political Economy 106(3) (June 1998): 514-550.

[34] Manning, Alan. Monopsony in Motion: Imperfect Competition in Labor Markets. Princeton, NJ: Princeton University Press, 2003.

[35] Millard, Stephen P., and Dale T. Mortensen. "The Unemployment and Welfare Effects of Labour Market Policy: A Comparison of the U.S. and U.K." In Unemployment Policy: How Should Governments Respond to Unemployment? edited by Dennis J. Snower and Guillermo de la Dehesa. Cambridge: Cambridge University Press, 1997.

[36] Mortensen, Dale T. "Specific Capital and Labor Turnover." Bell Journal of Economics 9(2) (Autumn 1978): 572-586.

[37] Mortensen, Dale T. "Property Rights and Efficiency in Mating, Racing, and Related Games." American Economic Review 72(5) (1982): 968-979.

[38] Mortensen, Dale T. "The Persistence and Indeterminacy of Unemployment in Search Equilibrium." Scandinavian Journal of Economics 91(2) (1989): 347-370.

[39] Mortensen, Dale T. Wage Dispersion: Why Are Similar Workers Paid Differently? Cambridge, MA: MIT Press, 2003. 
[40] Mortensen, Dale T., and Christopher A. Pissarides. "Job Creation and Destruction in the Theory of Unemployment." Review of Economic Studies 61(3) (July 1994): 397-415.

[41] Mortensen, Dale T., and Christopher A. Pissarides. "Unemployment Responses to 'SkillBiased' Technology Shocks: The Role of Labour Market Policy." Economic Journal 109 (April 1999): 242-265.

[42] Pissarides, Christopher A. "Efficient Job Rejection." Economic Journal 94 (Supplement 1984): $97-108$.

[43] Pissarides, Christopher A. "Short-Run Equilibrium Dynamics of Unemployment, Vacancies, and Real Wages." American Economic Review 75 (September 1985): 676-690.

[44] Pissarides, Christopher A. "Search Unemployment with On-the-job Search." Review of Economic Studies 61(3) (July 1994): 457-475.

[45] Pissarides, Christopher A. Equilibrium Unemployment Theory. Cambridge, MA: MIT Press, 2000 (second edition).

[46] Postel-Vinay, Fabien, and Jean-Marc Robin. "Wage Dispersion with Worker and Employer Heterogeneity." Econometrica 70(6) (November 2002): 2295-2350.

[47] Pries, Michael, and Richard Rogerson. "Hiring Policies, Labor Market Institutions, and Labor Market Flows." Journal of Political Economy 113(4) (August 2005): 811-839.

[48] Shimer, Robert. "On-the-Job Search, Bargaining, and Wage Dispersion." University of Chicago mimeo, 2004.

[49] Shimer, Robert, and Lones Smith. "Assortative Matching and Search." Econometrica 68(2) (March 2000): 343-369.

[50] Shimer, Robert, and Lones Smith. "Nonstationary Search." University of Chicago and University of Michigan mimeo, 2001. 
[51] Van den Berg, Gerard J., and Geert Ridder. "An Empirical Equilibrium Search Model of the Labor Market.” Econometrica 66(5) (September 1998): 1183-1221.

[52] Violante, Giovanni L. "Technological Acceleration, Skill Transferability, and the Rise in Residual Inequality." Quarterly Journal of Economics 117(1) (February 2002): 297-338.

[53] Wolinski, Asher. "Matching, Search, and Bargaining." Journal of Economic Theory 42 (1987): 311-333. 


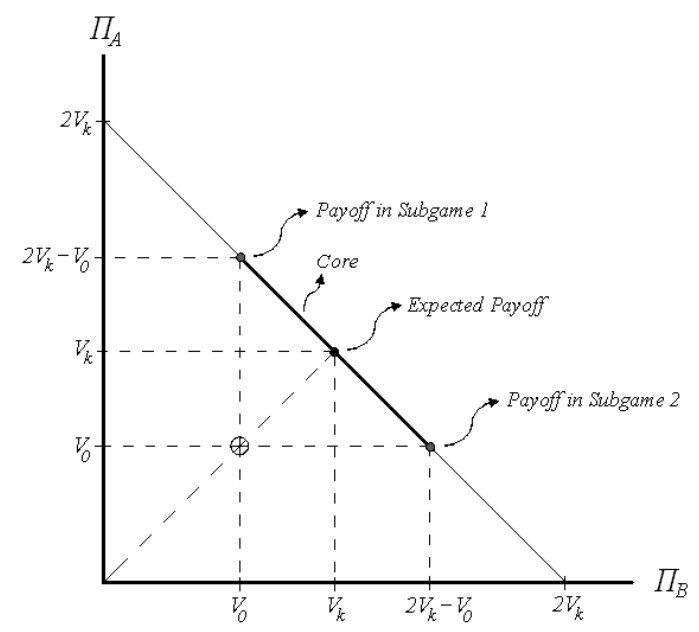

Figure 8: Core payoffs for a meeting involving two agents.
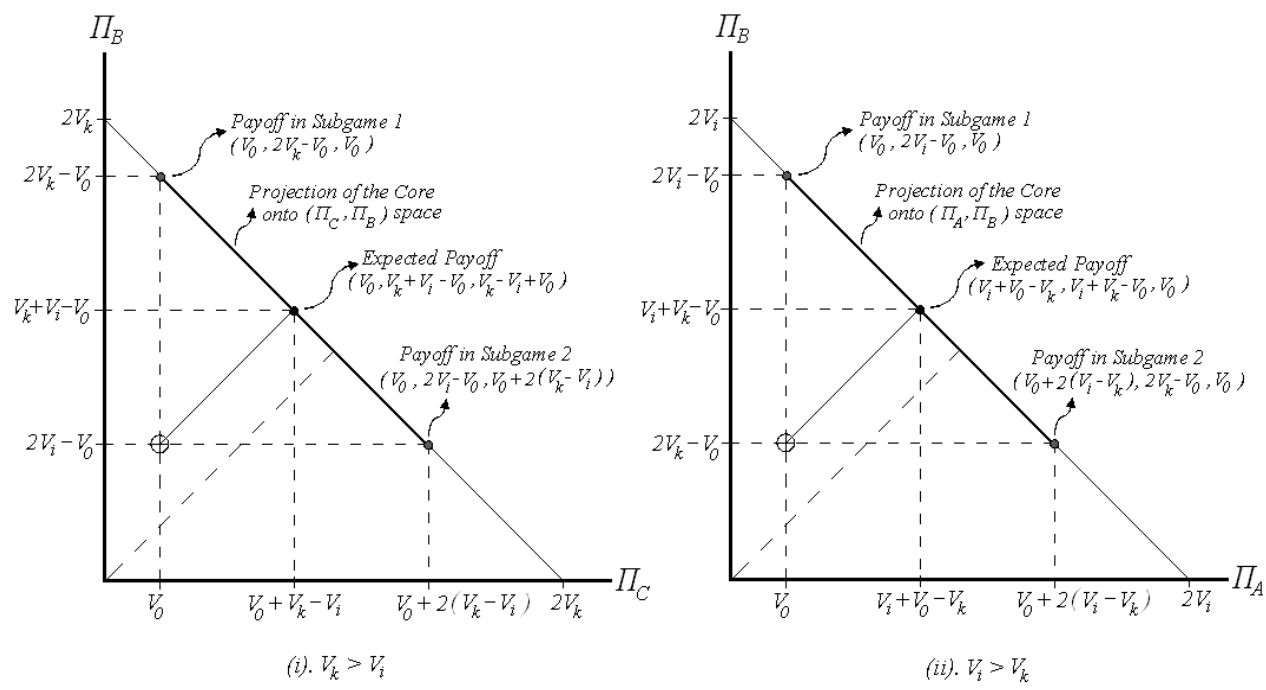

Figure 9: Core payoffs for a meeting involving three agents. 